\title{
Kidney and uro-trauma: WSES-AAST guidelines
}

\author{
Federico Coccolini ${ }^{1 *}$, Ernest E. Moore ${ }^{2}$, Yoram Kluger ${ }^{3}$, Walter Biffl ${ }^{4}$, Ari Leppaniemi ${ }^{5}$, Yosuke Matsumura ${ }^{6}$, \\ Fernando Kim7, Andrew B. Peitzman ${ }^{8}$, Gustavo P. Fraga ${ }^{9}$, Massimo Sartelli ${ }^{10}$, Luca Ansaloni ${ }^{11}$, Goran Augustin ${ }^{12}$, \\ Andrew Kirkpatrick ${ }^{13}$, Fikri Abu-Zidan ${ }^{14}$, Imitiaz Wani $^{15}$, Dieter Weber ${ }^{16}$, Emmanouil Pikoulis $^{17}$, Martha Larrea ${ }^{18}$, \\ Catherine Arvieux ${ }^{19}$, Vassil Manchev ${ }^{20}$, Viktor Reva ${ }^{21}$, Raul Coimbra ${ }^{22}$, Vladimir Khokha ${ }^{23}$, Alain Chichom Mefire ${ }^{24}$, \\ Carlos Ordonez ${ }^{25}$, Massimo Chiarugi ${ }^{1}$, Fernando Machado ${ }^{26}$, Boris Sakakushev ${ }^{27}$, Junichi Matsumoto ${ }^{28}$, Ron Maier ${ }^{29}$, \\ Isidoro di Carlo ${ }^{30}$, Fausto Catena ${ }^{31}$ and WSES-AAST Expert Panel
}

\begin{abstract}
Renal and urogenital injuries occur in approximately 10-20\% of abdominal trauma in adults and children. Optimal management should take into consideration the anatomic injury, the hemodynamic status, and the associated injuries. The management of urogenital trauma aims to restore homeostasis and normal physiology especially in pediatric patients where non-operative management is considered the gold standard. As with all traumatic conditions, the management of urogenital trauma should be multidisciplinary including urologists, interventional radiologists, and trauma surgeons, as well as emergency and ICU physicians. The aim of this paper is to present the World Society of Emergency Surgery (WSES) and the American Association for the Surgery of Trauma (AAST) kidney and urogenital trauma management guidelines.
\end{abstract}

Keywords: Kidney, Urogenital, Urethra, Ureter, Bladder, Trauma, Adult, Pediatric, Classification, Guidelines, Embolization, Surgery, Operative, Non-operative, Conservative, Stenting, Urological, Endovascular trauma management, Flow chart

\section{Background}

In both, adult and children cohorts, urogenital trauma has a cumulative incidence of $10-20 \%$, and the kidney is involved in $65-90 \%$ of the time [1-3]. Males are involved 3 times more than females (both in adults and children) [2,4]. As in other abdominal injuries, the use of non-operative management (NOM) has significantly increased in last decades, particularly due to the introduction of hybrid rooms and endovascular trauma and bleeding management (EVTM) associated with modern urological mini-invasive procedures $[5,6]$. Moreover, In pediatric patients, NOM should be the first option as soon as it is viable and safe. However, operative management $(\mathrm{OM})$ remains the gold standard in unstable patients, after failure of NOM (fNOM), and in many

\footnotetext{
* Correspondence: federico.coccolini@gmail.com

${ }^{1}$ General, Emergency and Trauma Surgery, Pisa University Hospital, Via

Paradisia, 56124 Pisa, Italy

Full list of author information is available at the end of the article
}

injuries caused by penetrating mechanisms; in fact, in gunshot and stab wounds, OM is applied in $75 \%$ and $50 \%$ of cases, respectively [1]. As for the other abdominopelvic lesion management, decisions should be based on physiology, anatomy, and associated injuries [6-9]. Another important consideration relates to the different management approach to kidney and urological trauma urologists and trauma surgeons [10]. Urologic guidelines tend in general to focus more on organ preservation, whereas trauma surgeons tend to consider the stabilization of physiology more importantly than organ preservation [10]. Despite this different point of view, an integrated approach and active collaboration between the two specialties forms the basis to achieve optimal management and the best outcomes [10]. This is particularly true for urogenital and urinary tract injuries in which the multidisciplinary approach is the cornerstone to improve short- and long-term outcomes.

(C) The Author(s). 2019 Open Access This article is distributed under the terms of the Creative Commons Attribution 4.0 International License (http://creativecommons.org/licenses/by/4.0/), which permits unrestricted use, distribution, and reproduction in any medium, provided you give appropriate credit to the original author(s) and the source, provide a link to the Creative Commons license, and indicate if changes were made. The Creative Commons Public Domain Dedication waiver (http://creativecommons.org/publicdomain/zero/1.0/) applies to the data made available in this article, unless otherwise stated. 


\section{Notes on the use of the guidelines}

The guidelines are evidence-based, with the grade of recommendation based on the evidence. The guidelines present the diagnostic and therapeutic methods for optimal management of urogenital trauma. The practice guidelines promulgated in this work do not represent a standard of practice. They are suggested plans of care, based on the best available evidence and the consensus of experts, but they do not exclude other approaches as being within the standard of practice. For example, they should not be used to compel adherence to a given method of medical management, which method should be finally determined after taking account of the conditions at the relevant medical institution (staff levels, experience, equipment, etc.) and the characteristics of the individual patient. However, responsibility for the results of treatment rests with those who are directly engaged therein, and not with the consensus group.

\section{Methods}

A computerized search was done by the bibliographer in different databanks (MEDLINE, Scopus, EMBASE) and citations were included for the period between January 1990 and August 2018 using the primary search strategy: kidney, injuries, trauma, urogenital, adult, pediatric, hemodynamic instability/stability, angioembolization, management, nonoperative, conservative, operative, surgery, diagnosis, follow-up, combined with AND/OR. No search restrictions were imposed. The dates were selected to allow comprehensive published abstracts of clinical trials, consensus conference, comparative studies, congresses, guidelines, government publication, multicenter studies, systematic reviews, meta-analysis, large case series, original articles, and randomized controlled trials. Case reports and small case series were excluded. Narrative review articles were also analyzed to determine if other cited studies should be included. The literature selection is reported in the flow chart (Fig. 1).

The level of evidence (LE) was evaluated using the GRADE system [11] (Table 1).

A group of experts in the field coordinated by a central coordinator was contacted to express their evidence-based opinion on several issues about the pediatric $(<16$ years old) and adult urogenital trauma $[12,13]$. Urogenital trauma was assessed by the anatomy of the injury (kidney, urogenital tract, bladder), type of injury (blunt and penetrating injury), management (conservative and operative management), and type of patient (adults, pediatrics). Through the Delphi

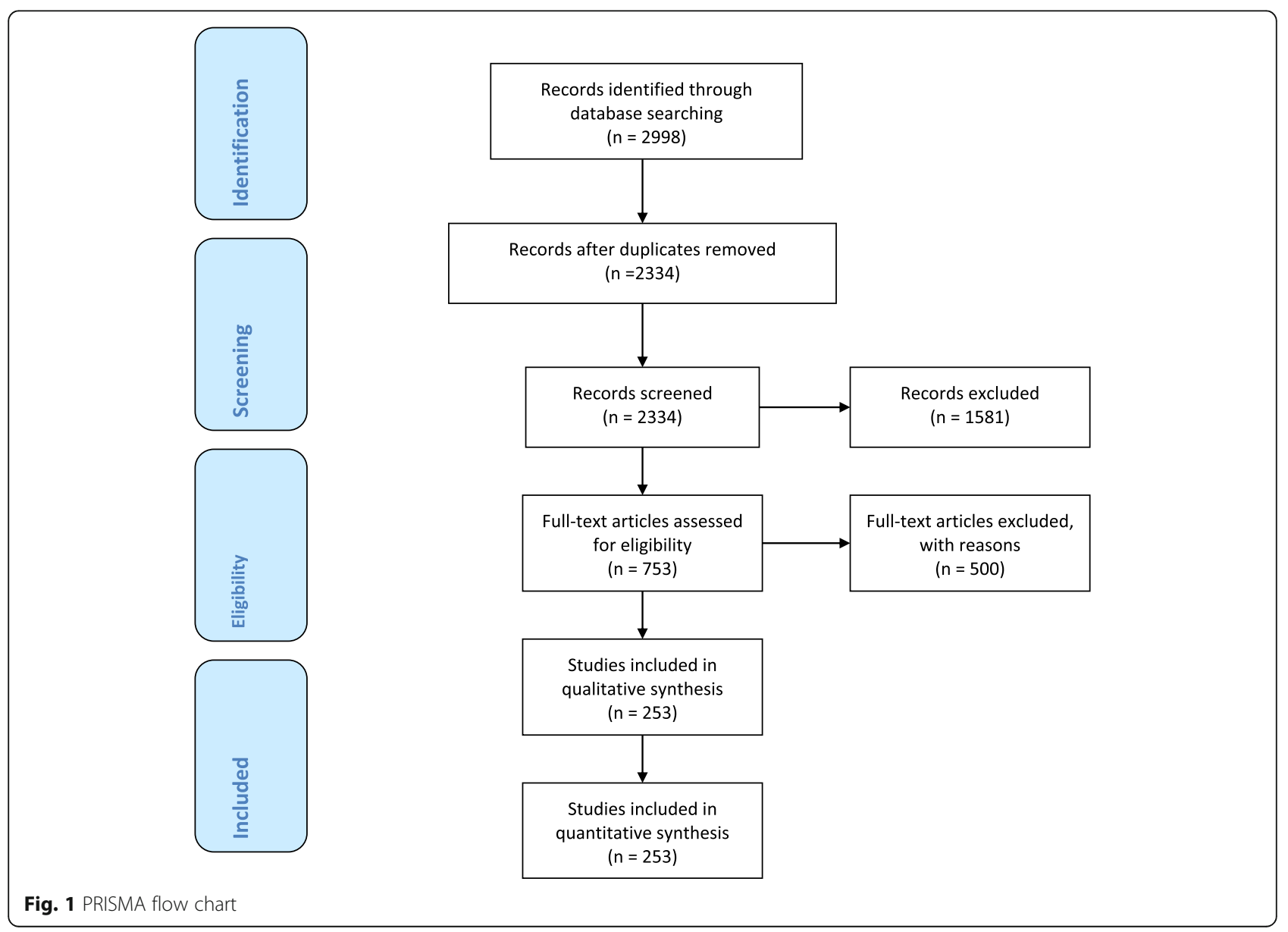




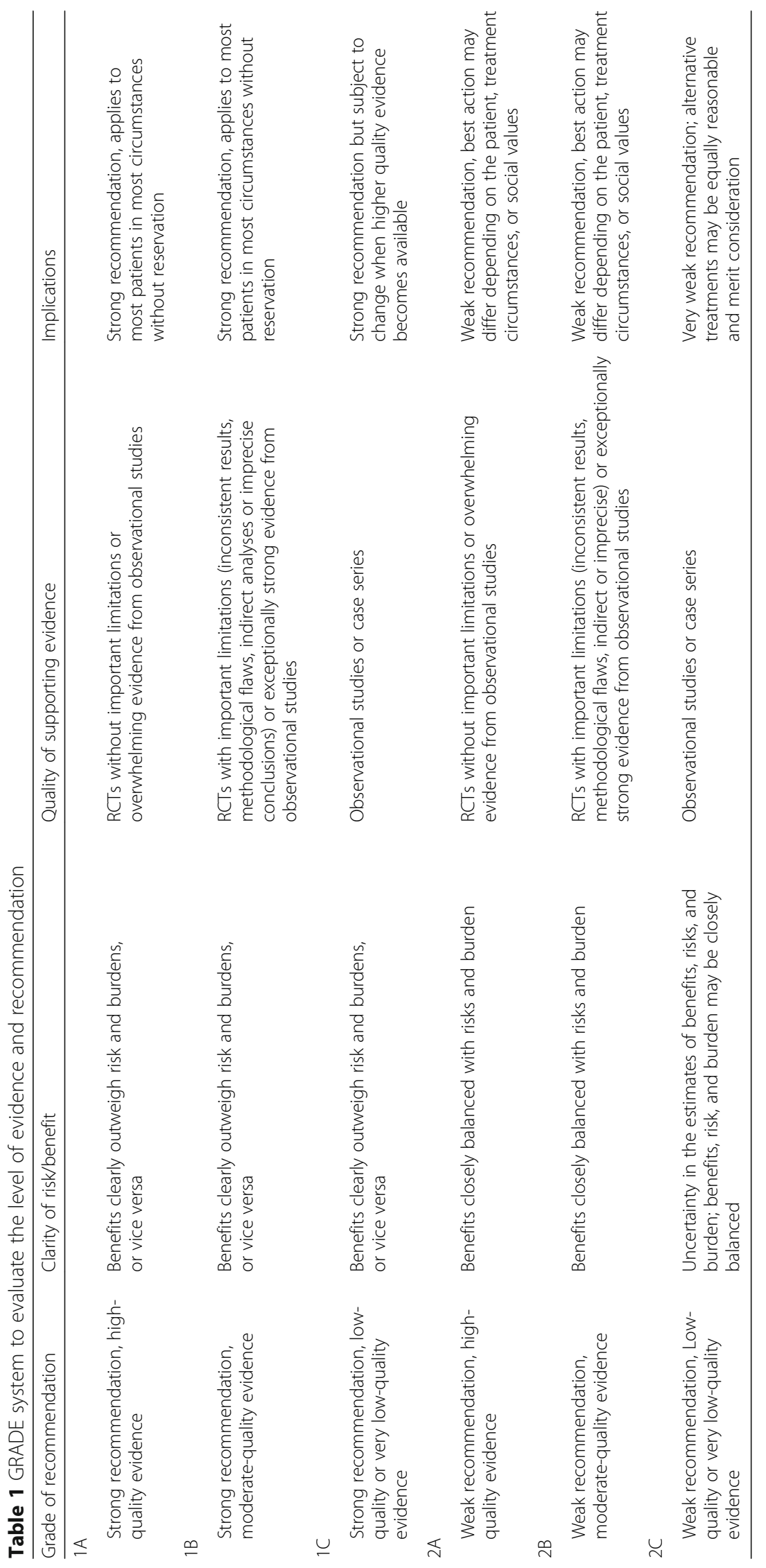


process, different issues were discussed in subsequent rounds. The central coordinator assembled the different answers derived from each round. Each version was then revised and improved. The definitive version was discussed during the WSES World Congress (in June 2019 in Njimengen, The Netherlands) by a combined expert group from both societies (WSES-AAST). The final version about which the agreement was reached resulted in the present manuscript. Statements are summarized in Table 3.

\section{Definitions}

In adult patients, hemodynamic instability is considered the condition in which admission systolic blood pressure upon admission is $<90 \mathrm{mmHg}$ with evidence of skin vasoconstriction (cool, clammy, decreased capillary refill), altered level of consciousness and/or shortness of breath, or $>90 \mathrm{mmHg}$ but requiring bolus infusions/ transfusions and/or vasopressor drugs and/or admission base excess $(\mathrm{BE})>-5 \mathrm{mmol} / \mathrm{l}$ and/or shock index $>1$ and/or transfusion requirement of at least 4-6 Units of packed red blood cells within the first $24 \mathrm{~h}$. Transient responder patients (adult and pediatric) are those showing an initial response to adequate fluid resuscitation, but then subsequent signs of ongoing blood loss and perfusion deficits. These patients have an initial response to therapy but do not reach sufficient stabilization to undergo interventional radiology procedures or NOM.

In pediatric patients, hemodynamic stability is considered a systolic blood pressure of $90 \mathrm{mmHg}$ plus twice the child's age in years (the lower limit is inferior to 70 $\mathrm{mmHg}$ plus twice the child's age in years, or inferior to $50 \mathrm{mmHg}$ in some studies). An acceptable hemodynamic status in children is considered a positive response to fluid resuscitation: 3 boluses of $20 \mathrm{~mL} / \mathrm{kg}$ of crystalloid replacement should be administered before blood replacement leading to heart rate reduction, cleared sensorium, return of peripheral pulses, normal skin color, increase in blood pressure and urinary output, and an increase in warmth of the skin in the extremities. Clinical judgment however is fundamental in evaluating children.

\section{WSES classification}

The WSES Classification (Table 2) divides kidney injuries into four classes considering the AAST-OIS classification (Fig. 2) and the hemodynamic status (Table 3):
- Minor (WSES class I)

- Moderate (WSES class II)

- Severe (WSES class III and IV)

Minor kidney injuries:

- WSES class I includes hemodynamically stable AAST-OIS grade I-II blunt and penetrating lesions.

\section{Moderate kidney injuries:}

- WSES class II includes hemodynamically stable AAST-OIS grade III blunt and penetrating lesions.

\section{Severe kidney injuries:}

- WSES class III includes hemodynamically stable AAST-OIS grade IV-V blunt and penetrating lesions and any grade parenchymal lesion with arterial dissection/occlusion.

- WSES class $\boldsymbol{I V}$ includes hemodynamically unstable AAST-OIS grade I-V blunt and penetrating lesions

Based on the present classification, WSES and AAST suggest a management algorithm for kidney injury shown in Fig. 3 and for urogenital tract injuries in Fig. 4.

\section{Patient stratification}

During the initial evaluation the hemodynamic status, mechanism of injury, presence of associated injuries, and anamnestic data must be considered (i.e., previous renal injuries, previous renal surgery, congenital single or pathologic kidneys or diseases), especially in children.

In adults, the clinical examination in urogenital trauma should consider the presence of hematuria, flank/abdominal pain/contusion, rib fractures, and mechanism of trauma. Special attention should be given to pelvic trauma in which urethral injuries can be frequently missed but should ideally be diagnosed in the first hours [1]. Macro or micro-hematuria is frequently present (88-94\%) in cases of renal/urogenital trauma but it does not predict the grade of injury $[13,14]$. Macro-hematuria is more frequently associated with major renal injuries; however, in $10-25 \%$ of highgrade kidney injury hematuria is, the same being observed in $24-50 \%$ of ureteropelvic junction and renal hilum injuries $[13,15]$. In $0.1-0.5 \%$ of the patients, hemodynamic stability and micro-hematuria exist in the presence of a significant urinary tract injury $[5,16-18]$.

Table 2 WSES kidney trauma classification

\begin{tabular}{llll}
\hline & WSES grade & AAST & Hemodynamic \\
\hline Minor & WSES grade I & I-II & Stable \\
Moderate & WSES grade II & III or segmental vascular injuries & Stable \\
Severe & WSES grade III & IV-V or any grade parenchymal lesion & Stable \\
& & with main vessels dissection/occlusion & Unstable \\
\hline
\end{tabular}




\begin{tabular}{|c|c|l|}
\hline \multicolumn{3}{|c|}{ American Association for Surgery of Trauma Renal Injury Scale } \\
\hline \multirow{2}{*}{ Grade } & Type & \multicolumn{1}{|c|}{ Description } \\
\hline \multirow{2}{*}{ I } & Contusion & Microscopic or gross haematuria. Urological studies normal. \\
\cline { 2 - 3 } & Haematoma & Subcapsular, non-expanding without parenchymal laceration. \\
\hline \multirow{2}{*}{ II } & Haematoma & Non-expanding peri-renal haematoma confined to renal retroperitoneum. \\
\cline { 2 - 4 } & Laceration & $<1.0 \mathrm{~cm}$ parenchymal depth of renal cortex with no urinary extravasation. \\
\hline \multirow{2}{*}{ III } & Laceration & $>1.0 \mathrm{~cm}$ parenchymal depth of renal cortex w/out collecting system rupture or urinary extravasation. \\
\hline \multirow{2}{*}{ IV } & Laceration & Parenchymal laceration extending through renal cortex, medulla \& collecting system. \\
\cline { 2 - 4 } & Vascular & Main renal artery or vein injury with contained haemorrhage. \\
\hline \multirow{2}{*}{ V } & Laceration & Completely shattered kidney. \\
\cline { 2 - 3 } & Vascular & Avulsion of renal hilum that devascularises kidney. \\
\hline
\end{tabular}

Fig. 2 AAST organ injury scale for kidney trauma

In children, the kidney is commonly injured following blunt trauma because of many anatomical reasons: less perirenal fat, thinner abdominal muscles, lack of ossification of the rib cage, larger kidney size, and fetal kidney lobulations, making them more vulnerable to injury [2, 3, 19-23]. However, even in the pediatric population, there is no clear correlation between the presence and type of hematuria and the degree of kidney injury (36-40\% of renal injuries and in up to $24 \%$ of renal artery occlusions hematuria is absent) $[22,24]$. However, while micro-hematuria $(<50$ red blood cells (RBC) per high-power field (HPF)) is frequent in children due to the kidney anatomy and the presence of undiagnosed kidney diseases (1-36\%), macro-hematuria seems to be more related to major renal injuries [22, 24]. The general suggestion is to perform imaging investigation in all those patients with blunt trauma with $>50 \mathrm{RBCs} /$ HPF $[13,22]$. In order to refine the use of CT scan in children, however, other factors should be considered (i.e., mechanism of injury and its energy/degree of deceleration associated with physical findings such as hypotension, flank hematoma and ecchymosis, rib fractures, cutaneous signs in the abdomen, and a drop in hematocrit associated with any degree of hematuria) [3, 13, 14, 17, 19-22, 24-34]. On the other hand, in children with minimal symptoms and/or clinical findings and $<50$ RBCs/HPF, ultrasound (US), contrast-enhanced ultrasound (CEUS), Eco-Doppler, and clinical and blood test monitoring may be sufficient for the initial evaluation [22].

In penetrating injuries, the presence of hematuria does not correlate with the grade of kidney injury. However, penetrating injuries are commonly associated with other intraabdominal injuries [18, 26, 31, 35], therefore, independently from the degree of hematuria, all hemodynamically stable patients should be imaged following a penetrating mechanism of injury [18].

\section{Pathophysiology of injury Kidney}

The most common mechanism of injury involving the kidney is blunt trauma associated frequently to high-velocity deceleration (90\% of cases); whereas penetrating trauma (gunshot and stab wounds occur in 1.4-3.3\% [5, 16-18, 36]. However, these incidences depend on the geographic area of the world [37].

The kidney is well protected in the retroperitoneum; however, it is particularly vulnerable to blunt trauma accompanied by rapid deceleration because the kidney is fixed only by the renal pelvis in the uretero-pelvic junction and by the vascular pedicle. In adults, the most frequent blunt mechanisms are falls from height, assault, skiing accidents, and road traffic-related injuries. In children, sports injuries such as skiing, snowboarding, horse riding, and bicycle and motorcycle accidents are the most frequent $[2,3,14,21,23,38-40]$. In the pediatric population, isolated blunt injuries are more frequent and occur after 5 years of age, while penetrating injuries usually increase after 14 years of age [2, 4]. Penetrating trauma can affect the kidneys especially when the superior abdomen is involved [5]. Isolated penetrating kidney injuries are rare and renal vascular injuries are more frequent than in blunt trauma $[1,22]$. The majority of renal injuries (up to $90 \%$ ) are minor both in adults and children and involve the parenchyma or segmental vessels $[2,16]$. A unique and uncommon type of injury is the isolated renal arterial transection or intimal disruption which occurs particularly in cases of rapid deceleration [1].

\section{Ureter}

Traumatic ureteral lesions are rare (less than 1\%) [41, 42]. The most common cause of ureteral injury is penetrating 
Table 3 Statements summary

\begin{tabular}{|c|c|}
\hline \multicolumn{2}{|l|}{ Statements } \\
\hline Diagnostic & \\
\hline • Kidney & 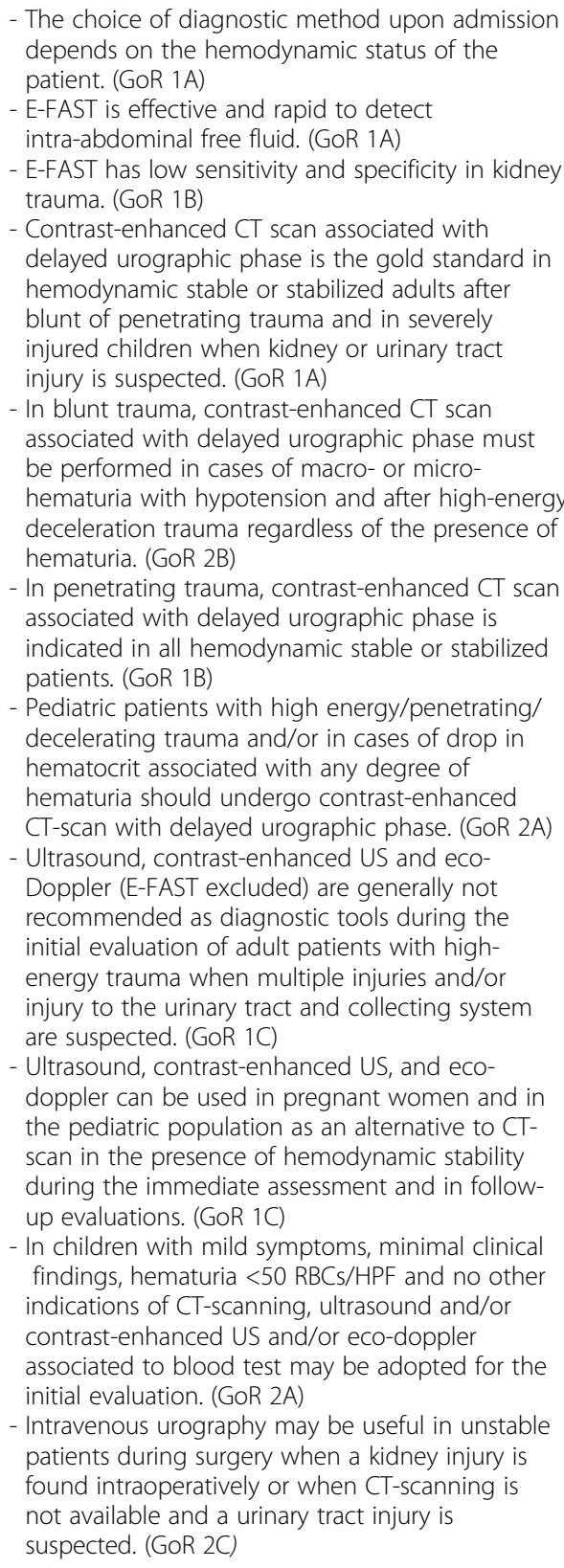 \\
\hline - Ureter & $\begin{array}{l}\text { - Injury to the ureter should be suspected in } \\
\text { high-energy blunt trauma, particularly in } \\
\text { deceleration injuries with multi-system } \\
\text { involvement and in all penetrating abdominal } \\
\text { trauma. (GoR 1C). } \\
\text { - Intravenous contrast-enhanced CT-scan with } \\
\text { delayed phase should be performed in } \\
\text { hemodynamically stable or stabilized patients if } \\
\text { ureteral injury is suspected (GoR 1C) } \\
\text { - Direct inspection of the ureter should be always } \\
\text { performed during emergency laparotomy in } \\
\text { patients with suspected ureteral injury. (GoR 1C) }\end{array}$ \\
\hline
\end{tabular}

- Bladder - Retrograde cystography (conventional radiography or CT-scan) represents the diagnostic procedure

Table 3 Statements summary (Continued)

Statements

of choice in bladder injuries. (GoR 1C)

- Retrograde cystography should be always performed in hemodynamically stable or stabilized patients with suspected bladder injury. (GoR 1C)

- Intravenous contrast-enhanced CT-scan with delayed phase is less sensitive and specific than retrograde cystography in detecting bladder injuries. (GoR 1B)

- In pelvic bleeding amenable to angioembolization associated to suspected bladder injuries, cystography should be postponed until the completion of the angiographic procedure to avoid affecting the accuracy of angiography. (GoR 2A)

- Direct inspection of the intraperitoneal bladder, whenever feasible, should always be performed during emergency laparotomy in patients with suspected bladder injury. Methylene blue or indigo carmine could be useful in intraoperative investigation. (GoR 1C)

- Urethra - Patients with post-traumatic urethral hemorrhage should be investigated for urethral injuries. (GoR 1C)

- During emergency laparotomy, if an urethral injury is suspected, it should be investigated directly whenever feasible. (GoR 2A)

- Retrograde urethrography and selective urethroscopy represent the modalities of choice to investigate traumatic urethral injuries. (GoR 1B) - In the event of penile lesions, urethroscopy should be preferred to retrograde uretrography (GoR 2A)

Management

Kidney

Non-operative management (NOM)

Kidney Angiography and
- NOM should be the treatment of choice for all hemodynamical stable or stabilized minor (AAST I-II), moderate (AAST III) and severe (AAST IV-V) lesions. (GoR 1B)

- Only in selected settings, with immediate availability of operating room, surgeons and adequate resuscitation, immediate access to blood, blood products and to high dependency / intensive care environment, and without other reasons for surgical exploration, NOM may be considered even in hemodynamically transient responder patients. (GoR 2C)

- In deciding for NOM in hemodynamically stable or stabilized patients, accurate classification of the degree of injury and associated injuries with CTscan with intravenous contrast and delayed urographic phases is mandatory. (GoR 2A)

- NOM in penetrating lateral kidney injuries is feasible and effective but accurate patient selection is crucial even in the absence of other indications for laparotomy. In particular, cases without violation of the peritoneal cavity are more suitable for NOM. (GoR 2A)

- Isolated urinary extravasation, in itself, is not an absolute contra-indication to NOM in absence of other indications for laparotomy. (GoR 1B)

- In low resource settings, NOM could be considered in hemodynamically stable patients without evidence of associated injuries, with negative serial physical examinations and negative first level imaging and blood tests. (GoR 2C)

- Angiography with eventual super-selective angioembolization is a safe and effective 
Table 3 Statements summary (Continued)

Statements

angioembolization procedure; it may be indicated in

hemodynamically stable or stabilized patients

with arterial contrast extravasation,

pseudoaneurysms, arteriovenous fistula, and

non-self-limiting gross hematuria. (GoR 1C)

- Angioembolization should be performed as selectively as possible. (GoR 1C)

- Blind-angioembolization is not indicated in hemodynamically stable or stabilized patients with both kidneys when angiography is negative for active bleeding, regardless of arterial contrast extravasation on CT-scan. (GoR 1C)

- In hemodynamically stable or stabilized patients with severe renal trauma with main renal artery injury, dissection or occlusion, angioembolization and/or percutaneous revascularization with stent or stentgraft is indicated in specialized centres and in patients with limited warm ischemia time (<240 min) (GoR 2C)

- Endovascular selective balloon occlusion of the renal artery could be utilized as a bridge to definitive hemostasis. This procedure requires direct visualization by fluoroscopy where the balloon is advanced over a selectively placed guidewire. (GoR 2B)

- In severe injury with main renal vein injury without self-limiting bleeding, angioembolization is not indicated. Patients should undergo surgical intervention. (GoR 1C)

- In hemodynamically stable or stabilized patients with solitary kidney and moderate (AAST III) or severe (AAST IV-V) renal trauma with arterial. contrast extravasation on CT-scan, angiography with eventual super-selective angioembolization should be considered as the first choice. (GoR 1C)

- In hemodynamically stable or stabilized patients with active kidney bleeding at angiography and without other indications for surgical intervention, in case of failure of the initial angioembolization, a repeat angioembolization should be considered. (GoR 1C)

- In adults, only in selected setting (immediate availability of operating room, surgeon, adequate resuscitation, immediate access to blood and blood products and to high dependency / intensive care environment) and without other reasons for surgical exploration, angioembolization might be considered in selected hemodynamically transient responder patients. (GoR 2C)

- In children, angiography and eventual superselective angioembolization should be the first choice even with active bleeding and labile hemodynamics, iof there is immediate availability of angiographic suite, immediate access to surgery and to blood and blood products, and to high dependency / intensive care environment. (GoR 2C)

Kidney Operative management
- Hemodynamically unstable and non-responder (WSES IV) patients should undergo OM. (GoR 2A)

- Resuscitative Endovascular Balloon Occlusion of the Aorta (i.e., REBOA) may be used in hemodynamically unstable patients as a bridge to other more definitive procedures for hemorrhage control. (GoR 2B)

- In cases of severe renal vascular injuries without self-limiting bleeding, OM is indicated. (GoR 1C)

- The presence of non-viable tissue (devascularized kidney) is not an indication to OM in the acute
Table 3 Statements summary (Continued)

Statements

setting in the absence of other indications for laparotomy. (GoR 2A)

- Hemodynamic stable or stabilized patients having damage to the renal pelvis not amenable to endoscopic/percutaeous techniques/stent should be considered for delayed $\mathrm{OM}$ in absence of other indications for immediate laparotomy. (GoR 2B)

Urinary tract injuries

- Ureter

- Contusions may require ureteral stenting when urine flow is impaired. (GoR 1C)

- Partial lesions of the ureter should be initially treated conservatively with the use of a stent, with or without a diverting nephrostomy in the absence of other indications for laparotomy. (GoR 1C)

- Partial and complete ureteral transections or avulsion not suitable for NOM may be treated with primary repair plus a double J stent or ureteral re-implant into the bladder in case of distal lesions (GoR 1C).

- Ureteral injuries should be repaired operatively when discovered during laparotomy or in cases where conservative management has failed (GoR 1C)

- Ureteral stenting should be attempted in cases of partial ureteral injuries diagnosed in a delayed fashion; if this approach fails, and/or in case of complete transection of the ureter, percutaneous nephrostomy with delayed surgical repair is indicated. (GoR 1C)

- In any ureteral repair, stent placement is strongly recommended. (GoR 1C)

- Bladder - Bladder contusion requires no specific treatment and might be observed clinically. (GoR 1C)

- Intraperitoneal bladder rupture should be managed by surgical exploration and primary repair (GoR 1B)

- Laparoscopy might be considered in repairing isolated intraperitoneal injuries in case of hemodynamic stability and no other indications for laparotomy. (GoR 2B)

- In case of severe intraperitoneal bladder rupture, during damage control procedures, urinary diversion via bladder and perivesical drainage or external ureteral stenting may be used. (GoR 1C) - Uncomplicated blunt or penetrating extraperitoneal bladder injuries may be managed non-operatively, with urinary drainage via a urethral or suprapubic catheter in the absence of other indication for laparotomy. (GoR 1C)

- Complex extra-peritoneal bladder ruptures-i.e., bladder neck injuries, lesions associated to pelvic ring fracture and/or vaginal or rectal injuriesshould be explored and repaired. (GoR 1C)

- Surgical repair of extraperitoneal bladder rupture should be considered during laparotomy for other indications and during surgical exploration of the prevesical space for orthopedic fixations. (GoR 1C) - In adult patients, urinary drainage with urethral catheter (without suprapubic catheter) after surgical management of bladder injuries is mandatory (GoR 1B); for pediatric patients suprapubic cystostomy is recommended (GoR 2C)

- Urethra $\quad$ - Urinary drainage should be obtained as soon as possible in case of traumatic urethral injury. 
Table 3 Statements summary (Continued)

\begin{tabular}{ll}
\hline Statements & (GoR 1C) \\
- Blunt anterior urethral injuries should be initially \\
managed conservatively with urinary drainage \\
(via urethral or suprapubic catheter); endoscopic \\
treatment with realignment should be attempted \\
before surgery. Delayed surgical repair should be \\
considered in case of failure of conservative \\
treatment after endoscopic approach. (GoR 1C) \\
- Partial blunt injuries of the posterior urethra may \\
be initially managed conservatively with urinary \\
drainage (via urethral or suprapubic catheter) and \\
endoscopic realignment; definitive surgical \\
management should be delayed for 14 days if no \\
other indications for laparotomy exist. (GoR 1C) \\
- Injuries of the posterior urethra in cases of \\
hemodynamic instability should be approached \\
by immediate urinary drainage and delayed \\
treatment. (GoR 1C) \\
- Conservative treatment of penetrating urethral \\
injuries is generally not recommended. (GoR 1C) \\
- Penetrating injuries of anterior urethra should be \\
treated with immediate direct surgical repair if the \\
clinical conditions allow and if an experienced \\
surgeon is available; otherwise, urinary drainage \\
should be performed and delayed treatment \\
planned. (GoR 1C) \\
- Penetrating injuries of the posterior urethra \\
should be treated with primary repair only if the \\
clinical conditions allow. Otherwise, urinary \\
drainage and delayed urethroplasty is \\
recommended. (GoR 1C) \\
- When posterior urethral injury is associated with \\
complex pelvic fracture, definitive surgical \\
treatment with urethroplasty should be \\
performed after the healing of pelvic ring injury. \\
(GoR 1C)
\end{tabular}

Short- and long-term follow-up

Kidney and urinary tract
- Follow-up imaging is not required for minor (AAST I-II) renal injuries managed non-operatively. (GoR 2B)

- In moderate (AAST III) and severe (AAST IV-V) renal injuries, the need for follow-up imaging is driven by the patients' clinical conditions. (GoR 2B)

- In severe injuries (AAST IV-V), contrast-enhanced CT scan with excretory phase (in cases with possible or documented urinary extravasation) or ultrasound and contrast-enhanced US are suggested within the first $48 \mathrm{~h}$ after trauma in adult patients and in delayed follow-up. (GoR 2A)

- Follow-up imaging in pediatric patients should be limited to moderate (AAST III) and severe

(AAST IV-V) injuries. (GoR 2B)

- In pediatric patients, ultrasound and contrastenhanced US should be the first choice in the early and delayed follow-up phases. If crosssectional imaging is required, magnetic resonance should be preferred. (GOR 2B)

- CT-scan with delayed phase imaging is the method of choice for the follow-up of ureteral and bladder injuries. (GoR 2A)

- Uretroscopy or uretrogram are the methods of choice for the follow-up of urethral injuries. (GoR 2A)

- Return to sport activities should be allowed only after microscopic hematuria is resolved. (GoR 2B) trauma, especially gunshot wounds [43-46]; only $1 / 3$ of cases are caused by blunt trauma [47]. As opposed to stab wounds, gunshot wounds can produce a blast effect even at a distance of $2 \mathrm{~cm}$ from the bullet path [41, 48]. In blunt trauma, ureteral injuries commonly happen at the ureteropelvic junction, especially in children and in high energy deceleration injuries [41, 44, 45, 48, 49]. Associated organ injuries are common in case of ureteral lesions $[42,45,50]$. The clinical presentation of ureteral injuries might be subtle but isolated hematuria is a common finding.

\section{Bladder}

Bladder injury is more frequent following blunt than penetrating trauma $(65-86 \%$ vs. $14-35 \%)$ [51-53]. In particular, bladder injury is present in $3.6 \%$ of abdominal gunshot injuries and $20 \%$ of penetrating buttock injuries $[41,48,54]$. Due to the high energy necessary to damage the bladder, 60 to $90 \%$ of patients presenting with bladder injury have a pelvic bony fracture while $6-8 \%$ of patients with a pelvic fracture will have bladder injury $[41,48,49,54]$. Pediatric patients are more susceptible to bladder injuries due to the children anatomy. However, bladder injuries in children are less associated with pelvic fractures than in adults [55]. A Pelvic fracture with hematuria is associated to a bladder injury in $30 \%$ of cases [45, 49]. Associated prostate-urethral injuries and rupture of the bladder occur in $10-29 \%$ male patients [45].

Bladder injuries are mainly of four types: intraperitoneal bladder rupture (IBR), extra-peritoneal bladder rupture (EBR), bladder contusion and bladder neck avulsion. IBR occurs in $15-25 \%$ of cases [ $41,45,48,49]$. EBR is the most common and is found in $60-90 \%$ of patients, and it is more frequently associated with pelvic fractures [48]. Combined Bladder Rupture (CBR), i.e., a combination of IBR and EBR, is found in $5-12 \%$ of cases $[41,48,56]$. EBR can be further classified into simple EBR, where the urinary leak is limited to the extraperitoneal pelvic region, and complex injuries where extravasated urine infiltrates the anterior abdominal wall, the scrotum, and the perineum [48].

\section{Urethra}

Urethral injuries are uncommon; they mostly affect male patients and are usually diagnosed following blunt trauma $[45,57]$. Urethral injuries are divided into anterior (bulbar and penile urethra) and posterior injuries (proximal to the perineal membrane, at the prostatic or membranous urethra). The main cause of anterior urethral injury is direct blunt trauma [45, 48, 50]. Penetrating injuries to the anterior urethra are rare and are mainly caused by gunshot injuries $[58,59]$.

Injuries to the posterior urethra usually result from pelvic trauma, Pelvic fracture urethral injury (PFUI), 


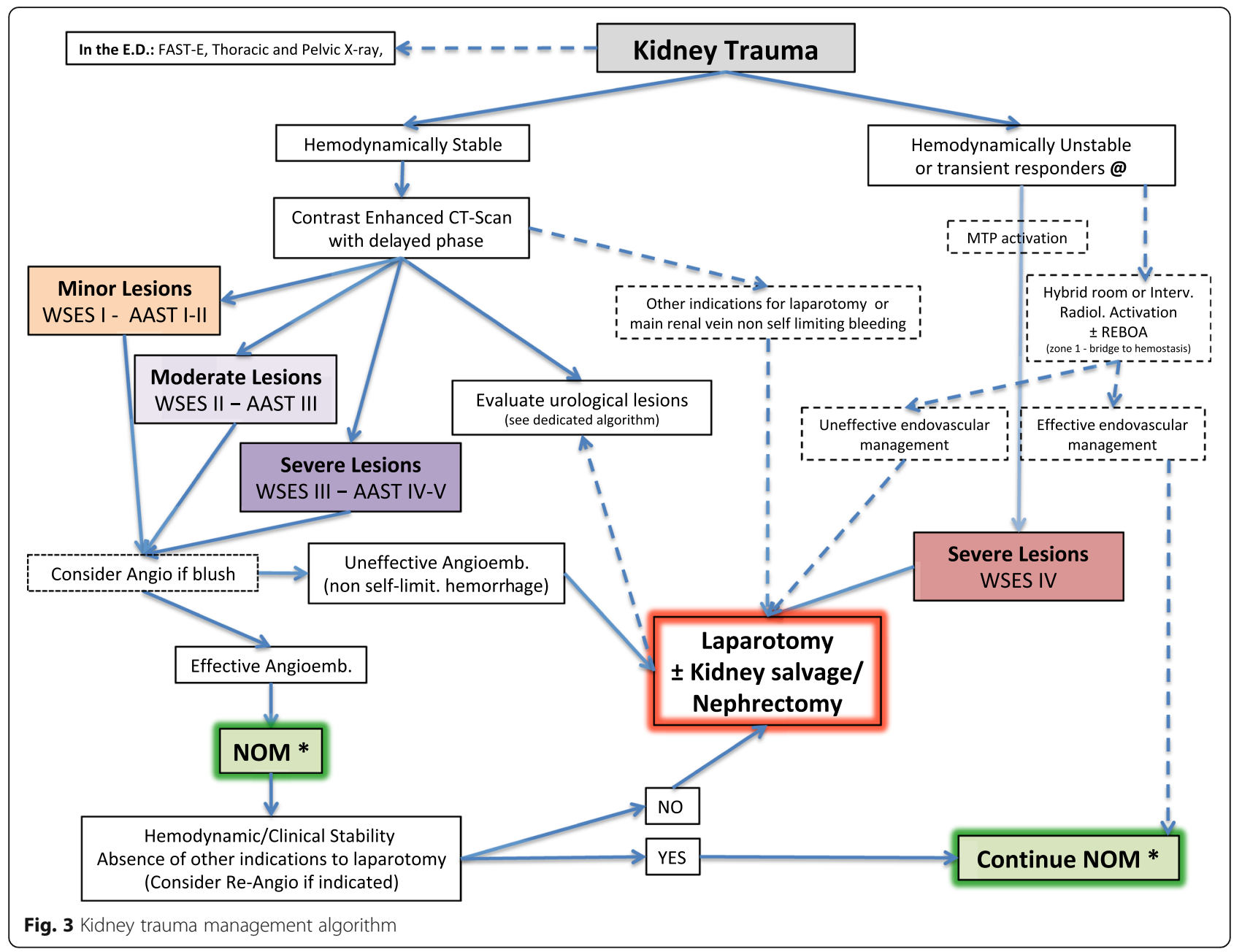

present in $1.5-5 \%$ of anterior pelvic fractures [60, 61]. The risk of urethral injury increases by $10 \%$ for every 1 $\mathrm{mm}$ increase in pubic symphysis diastasis [62]. Posterior urethral injuries may be classified as complete (65\% of lesions) or incomplete (35\% of cases) [63]. In complete injuries, a gap is present between the two injured stumps of the urethra. Penetrating injuries to the posterior urethra are extremely rare and are caused mainly by gunshot wounds; the risk of associated intra-abdominal lesions is high [64]. The Goldman classification of urethral injuries [65] includes five types of lesions aimed at discerning anterior from posterior and complete from incomplete and at determining whether posterior urethral injuries involve the bladder neck or the rectal wall. Associated urethral and bladder injuries are found in up to $20 \%$ of cases [66]. Female urethral injuries are uncommon and are often caused by pelvic injuries and are usually associated with rectal and vaginal injuries [67, 68].

\section{Diagnostic procedures}

There are no specific recommendations regarding the diagnosis of urogenital injuries in children. Therefore, pediatric patients should be investigated as adults considering the need to reduce, as much as possible, the exposure to ionizing radiation.

\section{Kidney}

- The choice of diagnostic method upon admission depends on the hemodynamic status of the patient. (GoR 1A)

- E-FAST is effective and rapid to detect intraabdominal free fluid. (GoR 1A)

- E-FAST has low sensitivity and specificity in kidney trauma. (GoR 1B)

- Contrast-enhanced CT scan associated with delayed urographic phase is the gold standard in hemodynamic stable or stabilized adults after blunt of penetrating trauma and in severely injured children when kidney or urinary tract injury is suspected. (GoR 1A)

- In blunt trauma, contrast-enhanced CT scan associated with delayed urographic phase must be performed in cases of macro- or micro-hematuria with 


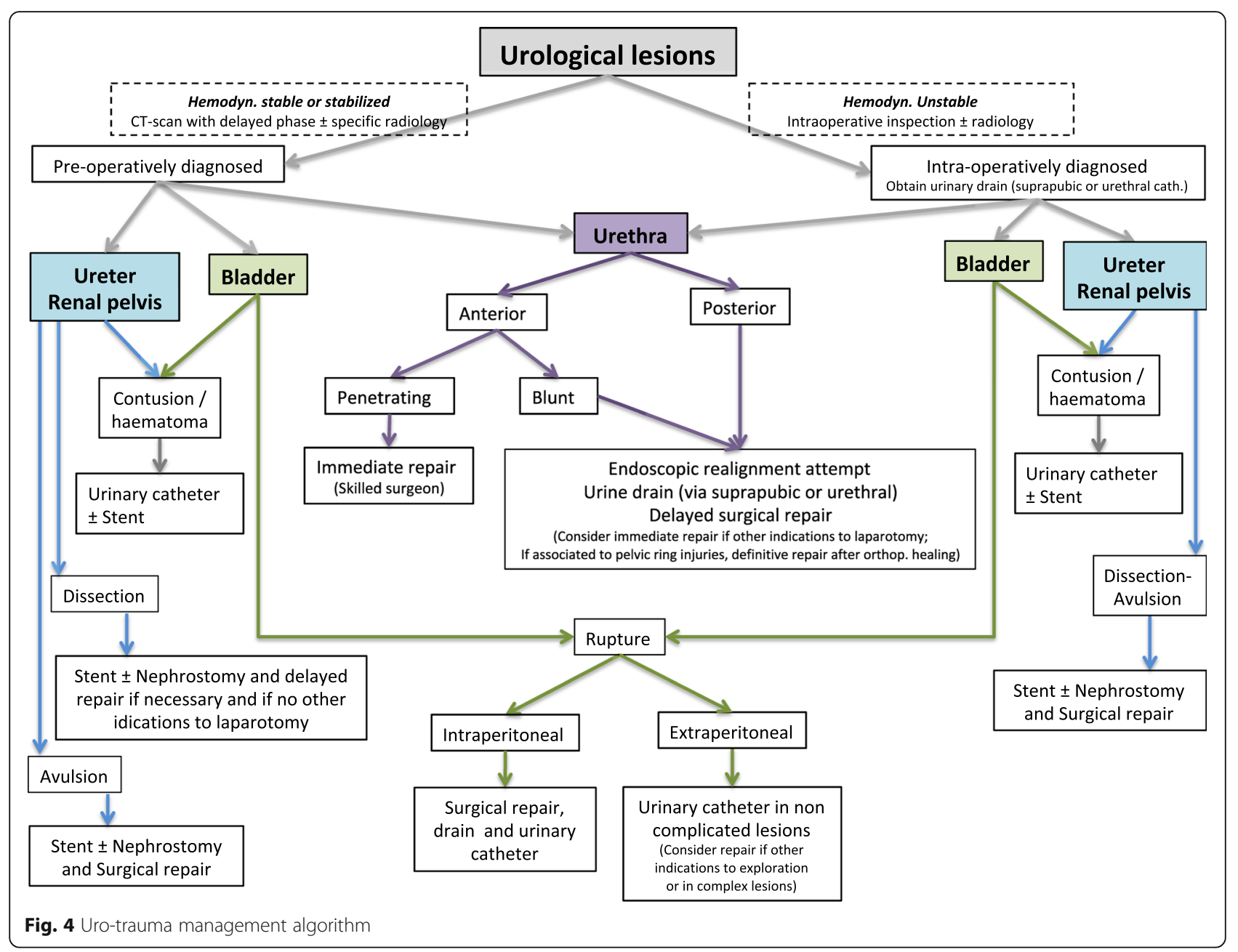

hypotension and after high-energy deceleration trauma regardless of the presence of hematuria. (GoR 2B)

- In penetrating trauma, contrast-enhanced CT scan associated with delayed urographic phase is indicated in all hemodynamic stable or stabilized patients. (GoR 1B)

- Pediatric patients with high energy/penetrating/ decelerating trauma and/or in cases of drop in hematocrit associated with any degree of hematuria should undergo contrast-enhanced CT-scan with delayed urographic phase. (GoR 2A)

- Ultrasound, contrast-enhanced US and eco-Doppler (E-FAST excluded) are generally not recommended as diagnostic tools during the initial evaluation of adult patients with high-energy trauma when multiple injuries and/or injury to the urinary tract and collecting system are suspected. (GoR 1C)

- Ultrasound, contrast-enhanced US, and eco-Doppler can be used in pregnant women and in the pediatric population as an alternative to CT scan in the presence of hemodynamic stability during the immediate assessment and in follow-up evaluations. (GoR 1C)
- In children with mild symptoms, minimal clinical findings, hematuria $<50$ RBCs/HPF and no other indications of CT-scanning, ultrasound and/or contrast-enhanced US and/or eco-doppler associated to blood test may be adopted for the initial evaluation. (GoR 2A)

- Intravenous urography may be useful in unstable patients during surgery when a kidney injury is found intraoperatively or when CT-scanning is not available and a urinary tract injury is suspected. (GoR 2C)

Extended-focused abdominal sonography for trauma (E-FAST), Ultrasonography, and Doppler-US (DUS) are useful and reliable noninvasive methods in trauma in general [69-71], however for the assessment of the kidney, due to anatomical reasons, these modalities may underestimate injuries (up to $30 \%$ ) with a sensitivity and specificity of $22-67 \%$ and $96-100 \%$, respectively $[5,14,16,17,72-76]$. In particular, vascular injuries are difficult to detect even using DUS [73]. 
In children, these are the methods of choice during follow-up excluding patients requiring CT-scan examination for other associated injuries [27, 77]. Usually, US/ DUS can be safely used in the first 36-48 h reserving CT for selected cases or in cases of anomalies seen on US/ DUS studies [22, 26, 77].

Contrast-enhanced US (CEUS) is not widely used $[74,78,79]$. Recent studies evaluated its use in abdominal trauma in the pediatric population and in fertile women as these methods seem to be effective in identifying extravasation, thrombosis, pseudoaneurysms (PSA), and post-traumautic arteriovenous fistulas [15, 80-86]. Contrast-enhanced US is thought to increase the accuracy of the E-FAST (above 80\%) in stable patients in whom renal injuries are suspected but with a negative FAST or in the presence of hematuria, severe abdominal trauma, fertile women, pediatric patients, and in immediate or middle/long-term follow-up [72, 74, 76, 79-81, 86-89]. Some authors suggest using CEUS in patients with moderate and severe injuries to identify bleeding and inject a hemostatic agent percutaneously [80, 87]. Innovative US techniques with real-time $3 \mathrm{D}$-enhanced imaging are promising in detecting ongoing hemorrhage [16, 90]. CEUS is not recommended in cases of suspicion of injury to the urinary tract and collecting system [85]. In these cases, contrast-enhanced CT-scan with late urographic phase is recommended.

CT scan with intravenous contrast is considered the gold standard in blunt and penetrating trauma [14, 15, $17,75,91-95]$. In renal and urogenital trauma, the arterial and venous phases $(20-30 \mathrm{~s}$ and $70-80 \mathrm{~s}$ of delay in acquiring the images, respectively) allow identification of almost all injuries and the addition of a 5-min delayed phase (excretory phase) permits the identification of urinary extravasation $[5,13,14,16,75,96-99]$. This delayed phase should be added selectively in case of suspicion of urogenital injuries. CT-scanning should always be considered in patients with associated severe brain injury and in any major injuries for the high probability of occurrence of associated injuries [100]. Three-dimensional CT reconstructions help in injury classification $[95,101,102]$. the CT cystogram is a useful and viable tool and more accurate than plain X-ray cystography [14].

CT-scanning allows the identification of patients with high-risk criteria for NOM failure such as contrast blush, perirenal hematoma > than $3.5 \mathrm{~cm}$, medial laceration with significant medial urinary extravasation (posteromedial blush/medial renal laceration) and lack of contrast in the ureter, suggesting a complete ureteropelvic junction disruption. The association of moderate or severe injuries and at least 2 of these criteria lead to a high rate to NOM failure [16, 103].

Routinely repeating CT scanning after trauma or in the follow-up phase is not recommended. A repeat CT- scan should be reserved for those cases with evident or suspected complications or significant clinical changes in moderate and severe injuries [15, 17, 75, 104, 105].

In the pediatric population, CT scanning to evaluate kidney injuries remains the gold standard in hemodynamic stable or stabilized patients with penetrating trauma or in cases where abdominal injuries are suspected independently to the grade of hematuria, when urogenital injury is suspected [10, 13, 20, 21, 24, 26, 33, 34, 106, 107]. In general, hospital CT-scan protocols should be adjusted to the ALARA (as low as reasonable achievable) principles of exposure to ionizing radiation $[24,106]$.

Retrograde urethrography, excretory urethrography, and intravenous urography

Intravenous urography (IVU) has been almost completely replaced by CT-scanning. However, it should be used in kidney injuries discovered during surgery in unstable patients, before opening the retroperitoneal hematoma. IVU can also be used when CT is not available or in low resource settings [3, 10, 13, 14, 18, 23, 36, $105,108]$. However, IVU is frequently used by urologists, more than by trauma surgeons [10]. The IVU false negative rate ranges between 37 and $75 \%$ [66].

The use of excretory urethrography has been reduced during the last decade in favor of contrast-enhanced CT-scan with delayed (excretory) phase [17]. However, in perineal trauma and/or in trauma in which pielouretral injuries, ureteral injuries, and bladder injuries are suspected, it might be useful $[5,109]$. Another affordable tool to evaluate the urethra, especially in the operating room or in low resource settings is retrograde urethrography. Documenting a normal urethra prior to urinary catheterization in cases with a high level of suspicion for urethral lesions is advisable.

\section{Magnetic resonance image}

MRI can be used to diagnose renal trauma in fertile/pregnant women, in pediatric patients, in cases of iodine allergy, in some cases when CT images are equivocal, and in the follow-up phase of urinary tract injuries [15, 85, 110-112].

\section{Ureter}

- Injury to the ureter should be suspected in highenergy blunt trauma, particularly in deceleration injuries with multi-system involvement and in all penetrating abdominal trauma. (GoR 1C).

- Intravenous contrast-enhanced CT-scan with delayed phase should be performed in hemodynamically stable or stabilized patients if ureteral injury is suspected (GoR 1C)

- Direct inspection of the ureter should be always performed during emergency laparotomy in patients with suspected ureteral injury. (GoR 1C)

Perirenal stranding or hematomas, extravasation of contrast into the perirenal space, low-density retroperitoneal 
fluid around the genitourinary elements at imaging are indicative of ureteral injuries $[49,113]$. Macro- and microscopic hematuria [114, 115] are not reliable signs of ureteral injury because its absence occurs in up to $25 \%$ of cases. A delay in the diagnosis may have a negative impact on outcomes $[41,113]$. Ultrasound plays no role in the diagnosis of ureteral injury [49]. At Ct-scan with delayed phase peri-ureteral hematoma, partial or complete obstruction of the lumen, mild distension of the ureter, hydronephrosis, delayed pyelogram, and the lack of contrast in the ureter distal to the injury, are all signs suggestive of ureteral injury [50]. Urinary ascites or urinoma are considered subacute/chronic findings [44, 48]. A 10-minute delayed-phase $\mathrm{CT}$-scan represents a valid diagnostic tool in the diagnosis of ureteral and ureteropelvic injuries $[41,113]$.

In case of unclear CT-scan results, an ascending urography represents the method of choice. IVU represents an unreliable test (false negatives up to 60\%) [44, 114].

In case of emergency laparotomy, direct inspection of the ureter is indicated and it can be associated with the use of renally excreted intravenous dye (i.e., indigo carmine or methylene blue) [50]. Single-shot IVU may be indicated intraoperatively.

\section{Bladder}

- Retrograde cystography (conventional radiography or CT-scan) represents the diagnostic procedure of choice in bladder injuries. (GoR 1C)

- Retrograde cystography should be always performed in hemodynamically stable or stabilized patients with suspected bladder injury. (GoR 1C)

- Intravenous contrast-enhanced CT-scan with delayed phase is less sensitive and specific than retrograde cystography in detecting bladder injuries. (GoR 1B)

- In pelvic bleeding amenable to angioembolization associated with suspected bladder injuries, cystography should be postponed until the completion of the angiographic procedure to avoid affecting the accuracy of angiography. (GoR 2A)

- Direct inspection of the intraperitoneal bladder, whenever feasible, should always be performed during emergency laparotomy in patients with suspected bladder injury. Methylene blue or indigo carmine could be useful in intraoperative investigation. (GoR 1C)

In the presence of a pelvic fracture, macro-hematuria is associated with a bladder injury in almost one-third of cases and therefore represents an absolute indication for imaging of the bladder [48, 50]. However, microhematuria is not an indication for mandatory radiologic evaluation. Cystography should always be considered if other indicators of bladder injury are present such as low urine output, abdominal distension, inability to void, suprapubic tenderness, uremia or elevated creatinine level and entrance/exit wounds in the lower abdomen, perineum, or buttocks [54].

Conventional or CT-scan cystography has similar sensitivity and specificity in identifying bladder injuries (for $95 \%$ and $100 \%$ respectively). Whenever possible CT-scan cystography would be preferred $[41,45,48,116-118] .$. If associated urethral injury is suspected, a retrograde urethrography should be obtained before bladder catheterization. Passive anterograde distension of the bladder with exclusive renal-excreted contrast by clamping of the urinary catheter during abdominopelvic CT is not an effective maneuver to diagnose bladder rupture due to the high false negative rate caused by the low intravesical urine pressure $[41,48,49,119]$. A technical pitfall of conventional cystography is represented by the false negative results in case of injuries located in the posterior wall: the lateral view is in fact rarely feasible due to the extent of pelvic injuries. In case a bladder injury is suspected in the presence of a bleeding pelvic fracture possibly amenable to angiographic management, caution should be used as extravasated contrast in the pelvis may impair the accuracy of the angiography [49].

\section{Urethra}

- Patients with post-traumatic urethral hemorrhage should be investigated for urethral injuries. (GoR 1C)

- During emergency laparotomy, if an urethral injury is suspected, it should be investigated directly whenever feasible. (GoR 2A)

- Retrograde urethrography and selective urethroscopy represent the modalities of choice to investigate traumatic urethral injuries. (GoR 1B)

- In the event of penile lesions, urethroscopy should be preferred to retrograde urethrography (GoR 2A)

Patients with urethral trauma may present with blood at the external urethral meatus, suprapubic fullness, perineal laceration, scrotal hematoma, urinary retention, difficulty or inability to insert a urinary catheter, and superiorly displaced prostate on rectal examination $[45,50,68,120,121]$.

If urethral injury is present or suspected, rectal and vaginal examination should be performed. Associated rectal injuries are present in up to $5 \%$ of cases [121, 122].

There are two diagnostic modalities: retrograde urethrography and flexible urethroscopy [12, 58, 68].

If urethral injury is suspected, retrograde urethrography is the procedure of choice and should be performed before attempting any other maneuvers on the genitourinary system $[45,48,66,123,124]$.

In case of hemodynamic instability, all the investigations on the urethra should be postponed and a urinary 
drainage, (i.e., suprapubic catheter) should be inserted. The placement of a urethral catheter should be postponed until urethrography is obtained.

Extravasation of contrast on retrograde urography indicates an urethral injury [45]. Pelvic MRI, although not indicated in the acute setting, represents a valuable tool for anatomic definition of the injury during the post-traumatic period [48].

A distinction between incomplete and complete urethral lesions is difficult; in general, incomplete lesions identified on retrograde urography are often characterized by extravasation of contrast which also fills the bladder, whereas extravasation of contrast is not accompanied by bladder filling in complete lesions [120].

In case of associated penile injuries and in women due to short urethra, urethroscopy is recommended over retrograde urethrography $[67,124-127]$.

\section{Management}

Kidney injuries

\section{Non-operative management}

- NOM should be the treatment of choice for all hemodynamical stable or stabilized minor (AAST III), moderate (AAST III) and severe (AAST IV-V) lesions. (GoR 1B)

- Only in selected settings, with immediate availability of operating room, surgeons and adequate resuscitation, immediate access to blood, blood products and to high dependency/intensive care environment, and without other reasons for surgical exploration, NOM may be considered even in hemodynamically transient responder patients. (GoR 2C)

- In deciding for NOM in hemodynamically stable or stabilized patients, accurate classification of the degree of injury and associated injuries with CT-scan with intravenous contrast and delayed urographic phases is mandatory. (GoR 2A)

- NOM in penetrating lateral kidney injuries is feasible and effective but accurate patient selection is crucial even in the absence of other indications for laparotomy. In particular, cases without violation of the peritoneal cavity are more suitable for NOM. (GoR 2A)

- Isolated urinary extravasation, in itself, is not an absolute contra-indication to NOM in absence of other indications for laparotomy. (GoR 1B)

- In low resource settings, NOM could be considered in hemodynamically stable patients without evidence of associated injuries, with negative serial physical examinations and negative first level imaging and blood tests. (GoR 2C)

No specific recommendations exist for NOM in blunt and penetrating kidney and urogenital tract injuries in children that are different than those used for adults. Therefore, pediatric patients should be treated as adult patients keeping into account the rule that being less invasive is better.

NOM in severe injuries should be considered only in those settings where close clinical observation and hemodynamic monitoring in a high dependency/intensive care environment are possible, including serial clinical examination and laboratory tests, immediate access to diagnostics, interventional radiology and surgery, and immediately available access to blood and blood products. Alternatively, NOM may be used selectively if a system for immediate transfer to a higher level of care facility exists. NOM should be considered a step-wise approach starting with conservative management, followed by the use of minimally invasive (endoscopic or angiographic) techniques $[92,116,128] .$. NOM lead to a higher renal preservation rate, a shorter hospital stay and a comparable complication rate to OM [128-141]. In hemodynamically stable or stabilized patients a CT scan with contrast together with delayed images is the gold standard to select patients for NOM $[1,17,43,92,108,116,118,130,131$, $133,135,138,139,141-160]$. Incomplete staging is a relative indication to surgical exploration [133, 156, 159-161]. Non-resolving urinomas are common complications of NOM requiring ureteric stenting or percutaneous drainage $[116,128,145,147,156,158,161]$; perirenal hematoma and renal fragmentation are not absolute indications for acute OM $[108,146,161]$.

Renal pelvis injury does not contraindicate NOM; however, it may request acute or delayed, endoscopic or open repair [17, 116, 147-149], particularly when complete avulsion of the ureteropelvic junction is observed.

Angioembolization of severe injuries allows continuation of NOM if after the procedure patients recovered from a hemodynamic point of view, and when no other indications for laparotomy exists $[1,17,43,116,118$, $135,147,150,154,161,162]$. In fact, In experienced centers with hybrid operating rooms, NOM may be attempted even in cases with a transient response to fluid resuscitation [1, 116] provided that all resources necessary for immediate operative intervention exist.

Isolated penetrating injuries to the kidney are rare; they are often associated with severe injuries, multiorgan involvement, and hemodynamic instability $[1,43,92,137$, $145,158,159,163]$. However, NOM may be an appropriate first-line management option in hemodynamically stable patients without other indications for open surgical exploration (peritonitis, failed embolization, persistent bleeding, expanding or pulsatile hematoma, pielo-ureteral lesions) following penetrating trauma $[1,43,92,116,128$, 129, 135, 136, 138, 143, 144, 146-149, 154, 156, 159, 161, $164,165]$. As for blunt trauma, in deciding the applicability of NOM, institutional factors must be considered [92, 
$116,128,130,132,135,141,143,147,150,160,161]$. Moreover, a multidisciplinary approach is needed [132, $141,143,144,161]$. It has been demonstrated that the degree of expertise of the trauma center plays a role in the successful rate of NOM [130, 132, 136, 161, 166]. Success rate of NOM is approximately $50 \%$ in stab wounds and $40 \%$ in gunshot wounds $[1,43,137,146,150,160]$.

Hemodynamically unstable patients with renal trauma not responsive to fluid resuscitation should undergo OM [1, 92, 108, 116, 142, 154-156, 158, 159].

No data exist regarding the best management strategy in low resource settings, although it seems rational to use $\mathrm{OM}$ in those circumstances. Low resource settings, in a limited sense, could be considered similar to military settings where lack of well-equipped hospital facilities, increased distance from trauma centers, and long transport time to definitive care facilities are the norm [167].

Other imaging modalities such as intravenous pyelography (less effective than $\mathrm{CT}$ in diagnosing significant renal injury) [43, 108, 116, 139, 154, 155, 158, 164], plain radiography [159], ultrasound (can lead to some significant false negative) $[116,139,155,157,159]$ should be used to assess hemodynamically stable patients when CT scanning is not available.

Serial physical examination is reliable in detecting significant injuries after penetrating trauma to the abdomen $[130,164,166]$ if performed by experienced clinicians and preferably by the same team.

\section{Operative management}

- Hemodynamically unstable and non-responder (WSES IV) patients should undergo OM. (GoR 2A)

- Resuscitative Endovascular Balloon Occlusion of the Aorta (i.e., REBOA) may be used in hemodynamically unstable patients as a bridge to other more definitive procedures for hemorrhage control. (GoR 2B)

- In cases of severe renal vascular injuries without selflimiting bleeding, OM is indicated. (GoR 1C)

- The presence of non-viable tissue (devascularized kidney) is not an indication to OM in the acute setting in the absence of other indications for laparotomy. (GoR 2A)

- Hemodynamic stable or stabilized patients having damage to the renal pelvis not amenable to endoscopic/percutaneous techniques/stent should be considered for delayed OM in absence of other indications for immediate laparotomy. (GoR 2B)

Uncontrollable life-threatening hemorrhage with avulsion of the renal pedicle and pulsating and/or expanding retroperitoneal hematoma or renal vein lesion without self-limiting hemorrhage are indications for OM. Retroperitoneal hematoma discovered during laparotomy and not adequately studied requires exploration of the kidney if they are pulsatile or if they are the only cause of hemodynamic instability. Whenever possible, the appropriate intraoperative diagnostic study should be performed $[10,13,15,18,75,132,136,137,168-179]$. All penetrating injuries associated with a retroperitoneal hematoma, if not adequately studied, should be explored especially if entering the peritoneal cavity $[15,137]$. A shattered kidney or avulsion of the pyelo-ureteral junction in a hemodynamically stable patient do not mandate urgent surgical intervention. Arterial injuries or severe parenchymal injuries often result in nephrectomy when discovered intraoperatively $[168,179]$. The success rate of arterial repair is $25-35 \%$ [15, 18, 177]. Arterial repair should be attempted in cases of patients with only one kidney or in those with bilateral renal injuries. Urine extravasation is not by itself an indication for $\mathrm{OM}$ in the acute setting $[18,169,180]$.

Some cases of renal injury result in significant devascularization of the organ which results in a significant renin-angiotensin-aldosterone cascade response. These patients may complain of flank pain and have unrelenting persistent hypertension not responsive to antihypertensives. In these rare instances, and when a contralateral kidney is functional, nephrectomy may be the only option if all other management strategies fail.

\section{Angiography and angioembolization}

- Angiography with eventual super-selective angioembolization is a safe and effective procedure; it may be indicated in hemodynamically stable or stabilized patients with arterial contrast extravasation, pseudoaneurysms, arteriovenous fistula, and non-self-limiting gross hematuria. (GoR 1C)

- Angioembolization should be performed as selectively as possible. (GoR 1C)

- Blind-angioembolization is not indicated in hemodynamically stable or stabilized patients with both kidneys when angiography is negative for active bleeding, regardless of arterial contrast extravasation on CT-scan. (GoR 1C)

- In hemodynamically stable or stabilized patients with severe renal trauma with main renal artery injury, dissection or occlusion, angioembolization and/or percutaneous revascularization with stent or stentgraft is indicated in specialized centers and in patients with limited warm ischemia time $(<240$ min) (GoR 2C)

- Endovascular selective balloon occlusion of the renal artery could be utilized as a bridge to definitive hemostasis. This procedure requires direct visualization by fluoroscopy where the balloon is advanced over a selectively placed guidewire. (GoR 2B)

- In severe injury with main renal vein injury without self-limiting bleeding, angioembolization is not indicated. Patients should undergo surgical intervention. (GoR 1C) 
- In hemodynamically stable or stabilized patients with solitary kidney and moderate (AAST III) or severe (AAST IV-V) renal trauma with arterial contrast extravasation on CT-scan, angiography with eventual super-selective angioembolization should be considered as the first choice. (GoR 1C)

- In hemodynamically stable or stabilized patients with active kidney bleeding at angiography and without other indications for surgical intervention, in case of failure of the initial angioembolization, a repeat angioembolization should be considered. (GoR 1C)

- In adults, only in selected setting (immediate availability of operating room, surgeon, adequate resuscitation, immediate access to blood and blood products and to high dependency / intensive care environment) and without other reasons for surgical exploration, angioembolization might be considered in selected hemodynamically transient responder patients. (GoR 2C)

- In children, angiography and eventual super-selective angioembolization should be the first choice even with active bleeding and labile hemodynamics, if there is immediate availability of angiographic suite, immediate access to surgery and to blood and blood products, and to high dependency / intensive care environment. (GoR 2C)

Indications to angiography and eventual selective angioembolization include arterial contrast extravasation on CT-scan in hemodynamically stable or transient responder patients [170, 181-188], gross non-self-limiting hematuria [188, 189], arteriovenous fistula [181, 188], Pseudoaneurysm (PSA) [188, 190] extended perirenal hematoma $[184,186,191,192]$ and progressive decrease in hemoglobin concentration during NOM $[185,188]$. Disrupted Gerota's fascia associated with contrast extravasation is suggested to increase the need for $\mathrm{AE}$ [192]. The grade of parenchymal disruption seems not to be associated with $\mathrm{AE}$ need even if severe renal injuries are associated with a reduced rate of $\mathrm{AE}$ success [170, 183, 186, 193]. Almost 32\% of blunt renal injuries with arterial contrast extravasation on CT-scan have negative angiography [182]; these cases can be successfully managed without AE [182]. Overall AE success rate in blunt renal trauma ranges from $63 \%$ to $100 \%$ [135, $162,181,185,188,189,194-200]$. In case of need for a repeat $\mathrm{AE}$, the success rate is similar to those seen in initial $\mathrm{AE}$, so re-interventions are justified when indicated by the clinical course [185]. Failure rates are linked to the experience of the centers [199]. AE seems to have better results in terms of renal function and ICU length of stay compared with nephrectomy, showing similar transfusion need and re-bleeding rates [200].
The anatomical damage to the kidney is associated with the need to repeat $\mathrm{AE}$ [193], but not with an overall $\mathrm{AE}$ failure [170]. Kidney devascularisation, initial hemodynamic instability, low hemoglobin concentration, the ISS, and associated injuries did not correlate with a higher rate of $\mathrm{AE}$ failure $[170,193]$. Age and volume of blood products given in the first $24 \mathrm{~h}$, the experience of the center, and penetrating trauma are associated with a higher risk of AE failure [193].

Renal AE has lower complication rates compared with surgery [162]. Renal dysfunction or renovascular hypertension directly linked to $\mathrm{AE}$ for renal injury is rare [162, 185, 186, 189, 197, 200-203].

Long-term follow-up showed good functional and morphological results in patients with single kidney [198]. Reported morbidity rate after $\mathrm{AE}$ is $25 \%[135,189,192]$ and includes accidental embolization of healthy arterial branches of vascularised territories, puncture-site bleeding, arterial dissection and thrombosis, contrast-induced nephropathy, post-embolization syndrome (i.e., back pain and fever), gross hematuria, renal abscess, coils migration, PSA and arteriovenous fistulae [162, 188, 189].

Shattered kidney without renal hilum avulsion could be treated with $\mathrm{AE}[185,194]$, but the management of renal pedicle avulsion is still a matter of debate, with some reporting $\mathrm{AE}$ success rates of $80 \%$ but with the need of repeat angioembolization in almost all cases $[170,193,204,205]$, and others reporting a failure rate of $100 \%$ [188].

Renal venous pedicle avulsion becomes the only contraindication for NOM and $\mathrm{AE}$ and requires immediate surgery $[181,186]$.

Accumulating evidence exists regarding the successful use of $\mathrm{AE}$ even in patients with severe trauma with liable hemodynamic parameters provided that the environment is adequate and risk is not increased [170, 186, 194, 204, 205]. In general, one in five penetrating kidney injury patients initially treated with conservatively will need either surgical or angiographic mamagement [206]. Reported AE success rate after renal stab wounds with vascular injuries is 82-88\% [203, 207]. Embolization should be performed as sub-selectively as possible to limit the associated parenchymal infarction [208]. Agents used for $\mathrm{AE}$ can induce either temporary or permanent arterial occlusion. The chosen embolic agents depend on the type of vascular injury (direct bleeding, PSA, arteriovenous fistula), but the majority of procedures are performed using coils with or without gelfoam [162].

Results of kidney artery surgical revascularization are poor, with long-term kidney function preservation rate of less than $25 \%$ [209, 210]. Conservative management of main renal artery occlusion leads to a high rate of severe hypertension, requiring subsequent nephrectomy. Percutaneous revascularization with stents showed better outcomes on renal function than surgical treatment 
$[209,210]$. However, it must be pointed out that warm ischemia time longer than 60 min leads to significant exponential losses in kidney function [211, 212]. The placement of a peripheral stent graft may be considered for hemostasis allowing perfusion of the renal artery distal to the injury site. Selective balloon occlusion can be considered as a temporary bleeding control maneuver prior to laparotomy however fluoroscopy is required for positioning of the guidewire and balloon catheter. Selective renal artery balloon occlusion leads to less global ischemia compared with aortic balloon occlusion.

Present guidelines and WSES classification consider segmental vascular injuries (SVI) as moderate lesions due to the reduced risk of organ loss and minor risk for life loss. Moreover, they have been separated from collecting system lacerations (CSL) as the overall NOM successful rate is significantly lower in SVI when compared with CLS (43\% vs. 98\%) [173]. SVI may be successfully treated with AE [116, 207].

The reported success rate of $\mathrm{AE}$ in children with blunt renal trauma and contrast medium extravasation or PSA is $100 \%$ with a major morbidity rate of $0 \%$ [213-215].

Current indications for $\mathrm{AE}$ in children are not universally recognized and include moderate and severe injuries, active bleeding with contrast blush on CT-scan, ongoing hemodynamic instability and PSA [215-217] with the suggestion to proceed with NOM only in those environments allowing for it without any additional risk. $\mathrm{AE}$ in pediatrics fills a void between NOM in the hemodynamically stable children and $\mathrm{OM}$ in the highly unstable patient with severe renal injury [217].

\section{Urinary tract injuries \\ Ureter}

- Contusions may require ureteral stenting when urine flow is impaired. (GoR 1C)

- Partial lesions of the ureter should be initially treated conservatively with the use of a stent, with or without a diverting nephrostomy in the absence of other indications for laparotomy. (GoR 1C)

- Partial and complete ureteral transections or avulsion not suitable for NOM may be treated with primary repair plus a double J stent or ureteral reimplant into the bladder in case of distal lesions (GoR 1C).

- Ureteral injuries should be repaired operatively when discovered during laparotomy or in cases where conservative management has failed (GoR 1C)

- Ureteral stenting should be attempted in cases of partial ureteral injuries diagnosed in a delayed fashion; if this approach fails, and/or in case of complete transection of the ureter, percutaneous nephrostomy with delayed surgical repair is indicated. (GoR 1C)
- In any ureteral repair, stent placement is strongly recommended. (GoR 1C)

In the absence of other indications for laparotomy, the majority of low-grade ureteral injuries (contusion or partial transection) may be managed by observation and/or ureteral stenting $[43,115]$. If stenting is unsuccessful, a nephrostomy tube should be placed [45]. If ureteral injuries are suspected during a laparotomy, direct visualization of the ureter is mandatory [43]. Whenever possible, ureteral injuries should be repaired. Otherwise, a damage control strategy should be preferred, with ligation of the damaged ureter and urinary diversion (temporary nephrostomy), followed by delayed repair $[45,50,115]$. In cases of complete transection of the ureter, surgical repair is indicated [43]. The two main options are primary uretero-ureterostomy or ureteral re-implant with bladder psoas hitch or a Boari flap [43, 50, 114, 115, 218]. The use of ureteral stents is recommended after all surgical repairs to reduce failures (leaks) and strictures [13, 42, 45, 50, $116,127]$. Distal injuries to the ureter (caudal to the iliac vessels) are usually treated by reimplantation of the ureter in the bladder (uretero-neocystostomy), as the traumatic insult may jeopardize the blood supply [42, 43, 45, 50, 218]. In cases of delayed diagnosis of incomplete ureteral injuries or delayed presentation, an attempt of ureteral stent placement should be done; however, retrograde stenting is often unsuccessful. In these cases, delayed surgical repair should be considered [219].

\section{Bladder}

- Bladder contusion requires no specific treatment and might be observed clinically. (GoR 1C)

- Intraperitoneal bladder rupture should be managed by surgical exploration and primary repair (GoR 1B)

- Laparoscopy might be considered in repairing isolated intraperitoneal injuries in case of hemodynamic stability and no other indications for laparotomy. (GoR 2B)

- In case of severe intraperitoneal bladder rupture, during damage control procedures, urinary diversion via bladder and perivesical drainage or external ureteral stenting may be used. (GoR 1C)

- Uncomplicated blunt or penetrating extraperitoneal bladder injuries may be managed non-operatively, with urinary drainage via a urethral or suprapubic catheter in the absence of other indications for laparotomy. (GoR 1C)

- Complex extra-peritoneal bladder ruptures-i.e., bladder neck injuries, lesions associated with pelvic ring fracture and/or vaginal or rectal injuries-should be explored and repaired. (GoR 1C)

- Surgical repair of extraperitoneal bladder rupture should be considered during laparotomy for other indications and during surgical exploration of the prevesical space for orthopedic fixations. (GoR 1C) 
- In adult patients, urinary drainage with urethral catheter (without suprapubic catheter) after surgical management of bladder injuries is mandatory (GoR 1B); for pediatric patients, suprapubic cystostomy is recommended (GoR 2C)

In cases of hemodynamic instability, urethral or suprapubic catheter may be inserted as a temporary measure and the repair of the bladder injury may be postponed [45].

All penetrating bladder injuries and Intraperitoneal bladder rupture (IBR) generally require surgical exploration and primary repair $[41,45,53]$. Laparoscopic repair of isolated IBR is a viable option [220]. Open surgical repair of bladder injuries is in a double-layer fashion using monofilament absorbable suture [54]. Single-layer repair is common during laparoscopic approach [12, 45, 54, 221, 222].

Uncomplicated blunt or penetrating EBR, in the absence of other indications for laparotomy, may be managed conservatively, with clinical observation, antibiotic prophylaxis and the insertion of a urethral catheter or a suprapubic percutaneous cystostomy, in case of a concomitant urethral injury [45]. Injury healing happens within 10 days in more than $85 \%$ of cases [53]. Surgical repair of EBR is indicated in complex injuries as bladder neck injuries or injuries associated with pelvic fractures requiring internal fixation and rectal or vaginal injuries $[41,50]$. Furthermore, surgical repair of EBR may be considered in case of non-resolution of urine extravasation 4 weeks after the traumatic event [45].

Gunshot injuries of the bladder are commonly associated to rectal injuries, which prompt fecal diversion. Commonly, these injuries are through-and-through (entry/exit site) requiring careful and complete pelvic inspection [222].

Urethral catheterization whenever possible has the same efficacy of suprapubic cystostomy; therefore routine placement of a suprapubic tube is no longer recommended [45, 223, 224]. Suprapubic catheterization may be reserved for cases with associated perineal injuries. Suprapubic drainage is recommended in children after the surgical repair of bladder rupture [225].

\section{Urethra}

- Urinary drainage should be obtained as soon as possible in case of traumatic urethral injury. (GoR 1C)

- Blunt anterior urethral injuries should be initially managed conservatively with urinary drainage (via urethral or suprapubic catheter); endoscopic treatment with realignment should be attempted before surgery. Delayed surgical repair should be considered in case of failure of conservative treatment after endoscopic approach. (GoR 1C)

- Partial blunt injuries of the posterior urethra may be initially managed conservatively with urinary drainage (via urethral or suprapubic catheter) and endoscopic realignment; definitive surgical management should be delayed for 14 days if no other indications for laparotomy exist. (GoR 1C)

- Injuries of the posterior urethra in cases of hemodynamic instability should be approached by immediate urinary drainage and delayed treatment. (GoR 1C)

- Conservative treatment of penetrating urethral injuries is generally not recommended. (GoR 1C)

- Penetrating injuries of anterior urethra should be treated with immediate direct surgical repair if the clinical conditions allow and if an experienced surgeon is available; otherwise, urinary drainage should be performed and delayed treatment planned. (GoR 1C)

- Penetrating injuries of the posterior urethra should be treated with primary repair only if the clinical conditions allow. Otherwise, urinary drainage and delayed urethroplasty are recommended. (GoR 1C)

- When posterior urethral injury is associated with complex pelvic fracture, definitive surgical treatment with urethroplasty should be performed after the healing of pelvic ring injury. (GoR 1C)

Bladder drainage should be obtained soon and as safe and technically feasible. In case of contrast extravasation on urethrogram, a suprapubic catheter should be considered $[57,226]$.

The treatment of choice in case of penetrating urethral injuries is surgical exploration and repair [227, 228]. Posterior urethral blunt injuries and selected penetrating partial injuries, in the absence of other indications for laparotomy, may be treated initially by NOM with the insertion of a suprapubic cystostomy or urethral catheter, as primary open realignment and primary open anastomosis are associated with high rates of stricture, urinary incontinence, and impotence [45, 50, 66, 123, 229].

However, the insertion of a suprapubic catheter may be difficult due to hematoma or to poor bladder filling in case of shock; an experienced provider may attempt once a careful urethral catheter placement $[58,60,61$, $67,120,125,126,226]$. However, if any resistance is encountered, a suprapubic catheter should be placed under direct visualization or with ultrasound guidance [120].

In case of anterior urethral blunt trauma, the initial treatment of choice is conservative with urinary drainage (by suprapubic or urethral catheter placement) and delayed treatment after an accurate evaluation of the extent of the injury. A trial of endoscopic realignment should be undertaken. In case of failure, surgery is recommended with urethroplasty $[67,230]$. Selected cases of incomplete penetrating injuries of the anterior urethra may be managed with trans-urethral catheter placement. 
Urethrography should be performed every two weeks until complete healing [122].

Unless other life-threatening injuries are present, uncomplicated penetrating lesions of the anterior urethra are best managed with prompt direct surgical repair [124]. Cases in which damage control procedures are needed or in which anastomotic urethroplasty is not feasible due to a large anatomic defect (typically lesions $>2-3 \mathrm{~cm}$ in the bulbar urethra and $>1.5 \mathrm{~cm}$ in the penile urethra), marsupialisation of the urethra, temporary suprapubic urinary catheter placement and delayed anatomic reconstruction with graft or flap (interval urethroplasty at $>3$ months) are indicated [45].

In blunt posterior urethral injuries, initial conservative treatment is recommended with planned delayed surgical treatment, allowing multidisciplinary management involving experienced surgeons and urologists [45].

In case of hemodynamically stable patients with complete lesions of the posterior urethra without other life-threatening injuries, immediate endoscopic realignment is preferred over immediate urethroplasty. Endoscopic realignment is associated with improved outcomes $[67,229,231,232]$. Therefore, immediate urethroplasty is not routinely recommended. When endoscopic realignment is unsuccessful, urinary drainage with suprapubic catheter placement and delayed urethroplasty are indicated [123, 229], preferably within 14 days from the injury. In case of associated pelvic fractures, definitive surgery should be postponed until after the healing of pelvic ring injuries [50, 126, 222, 231, 233, 234].

The management of penetrating injuries to the posterior urethra depends on the presence and severity of associated injuries. In case of life-threatening associated injuries and Damage Control approach, urinary diversion and delayed urethroplasty is advised [64, 127].In hemodynamic stable patients, without associated severe injuries, immediate retropubic exploration and primary repair of the injury is recommended $[64,126]$.

Follow-up:

- Follow-up imaging is not required for minor (AAST I-II) renal injuries managed non-operatively. (GoR 2B)

- In moderate (AAST III) and severe (AAST IV-V) renal injuries, the need for follow-up imaging is driven by the patients' clinical conditions. (GoR 2B)

- In severe injuries (AAST IV-V), contrast-enhanced CT scan with excretory phase (in cases with possible or documented urinary extravasation) or ultrasound and contrast-enhanced US are suggested within the first $48 \mathrm{~h}$ after trauma in adult patients and in delayed follow-up. (GoR 2A)

- Follow-up imaging in pediatric patients should be limited to moderate (AAST III) and severe (AAST $I V-V)$ injuries. (GoR 2B)
- In pediatric patients, ultrasound and contrastenhanced US should be the first choice in the early and delayed follow-up phases. If cross-sectional imaging is required, magnetic resonance should be preferred. (GoR 2B)

- CT-scan with delayed phase imaging is the method of choice for the follow-up of ureteral and bladder injuries. (GoR 2A)

- Ureteroscopy or urethrogram are the methods of choice for the follow-up of urethral injuries. (GoR 2A)

- Return to sport activities should be allowed only after microscopic hematuria is resolved. (GoR 2B)

In general mild and moderate injuries have a very low complication rate [235-237]. Routine follow-up imaging may not be justified for mild injuries [236-240]. In severe injuries, CT scan with delayed excretory phase is recommended within the first $48 \mathrm{~h}$ after admission as urinary leak may be missed on the initial CT scan in $0.2 \%$ of all cases and in $1 \%$ of high-grade renal injuries [105]..

Moderate injuries without urine extravasation would require follow-up imaging only in case of worsening of patient status [17, 236, 239, 241, 242].

The risk of secondary hemorrhage deserves particular mention. Secondary hemorrhage is usually caused by rupture of a PSA or arteriovenous fistula, which occurs in up to $25 \%$ of moderate/severe injuries [151, 243] within 2 weeks of the injury [151, 207, 243]. Hematuria is the most common sign suggesting these complications [151]. It is an indication to perform contrast-enhanced CT scan or DUS or CEUS, according to the availability of the tests in the hospital. These three techniques showed to be similar in reliability regarding the detection of these complications [77, 151].

No definitive evidence exists with regard to timing of return to normal activity after renal trauma. In general, bed rest or reduced activity is recommended until gross hematuria is resolved [146, 237, 244].

Return to sport activities after a minor or moderate renal injury may occur within 2 to 6 weeks from the injury while severe injuries may require longer periods $(6$ to 12 months) [245, 246]. As a general rule, sports activities should be avoided until microscopic hematuria is resolved [245, 246].

Limited low-grade evidence is available with regard to the best follow-up strategy in pediatric patients with renal trauma. US or CEUS may be considered the method of choice in moderate and severe renal injuries, even if initially evaluated by CT-scan [247]. If US or CEUS imaging is inconclusive MRI, if available, should be performed.

There is no sufficient evidence regarding the relationship between renal injury severity and the rate and timing of healing or incidence of renal dysfunction [247-249]. Low-grade kidney injuries have a very low rate of late 
complication in pediatric patients; therefore, scheduled imaging follow-up in the potential complications is not indicated $[247,250]$. The reported incidence of renal trauma-induced hypertension is $0-6.6 \%$ [244, 251-254], but in general, all those who are normotensive in the immediate post-trauma period usually do not develop signs of hypertension during follow-up [251].

\section{Conclusions}

The management of kidney and urogenital trauma is multidisciplinary. When feasible, non-operative management should always be considered as the first option. For this reason, the anatomy of the injury, its physiological effects, and the associated injuries should always be considered to define the best treatment strategy.

\section{Abbreviations}

AAST: American Association for Surgery for Trauma; AG/AE: Angiography/ angioembolization; ALARA: As low as reasonable achievable; BE: Base excess; CSL: Collecting system lacerations; CBR: Combined bladder rupture; CT: Computed tomography; CEUS: Contrast-enhanced ultrasound; DUS: Doppler-US; EVTM: Endovascular trauma and bleeding management; EFAST: Extended-focused abdominal sonography for trauma; EBR: Extraperitoneal bladder rupture; fNOM: Failure of NOM; GCS: Glasgow Coma Scale; HPF: High-power field; IBR: Intra-peritoneal bladder rupture; ISS: Injury severity score; IVU: Intravenous urography; LE: Level of evidence; MRI: Magnetic resonance image; MTP: Massive transfusion protocols; NOM: Non-operative management; OIS: Organ injury scale; OM: Operative management; PFUI: Pelvic fracture urethral injury; PSA: Pseudoaneurysm; RBCs: Red blood cells; REBOA: Resuscitative endovascular balloon occlusion of the aorta; SVI: Segmental vascular injuries; US: Ultrasound; WSES: World Society of Emergency Surgery

\section{Acknowledgements}

Special thanks to Ms. Franca Boschini (Bibliographer, Medical Library, Papa Giovanni XXIII Hospital, Bergamo, Italy) for the precious bibliographical work. Contributors:

\section{WSES-AAST Expert Panel}

Paola Fugazzola (1), Martijn Stommel (2), Mohan Rajashekar (3), Edward Tan (4), Matti Tolonen (5), Marco Ceresoli (6), Carlos Augusto Gomez (7), Niccolo Allievi (8), Mircea Chirica (9), Francesco Salvetti (10), Riccardo Bertelli (1), Offir Ben-Ishay (11), Hany Bahouth (11), Gianluca Baiocchi (12), Antonio Tarasconi (13). Stefania Cimbanassi (14), Osvaldo Chiara (14), Richard ten-Broek (2), Giulia Montori (15), Erika Picariello (1), Leonardo Solaini (16), Andreas Hecker (17), Matteo Tomasoni (1), Paola Perfetti (18), Neil Parry (19), Nicola DeAngelis (20), Bruno M Pereira (21), Joaquin Bado (22), jbado03@hotmail.com, Oreste Romeo (23), Andreas Pikoulis (24), Miklosh Bala (25), Lena Napolitano (23), Joseph Galante (26), Sandro Rizoli (27), Paula Ferrada (28), Tal Horer (29),

Megan Brenner (30), m.brenner@ruhealth.org, Rao Ivatury (28)

(1) General, Emergency and Trauma Surgery Dept., Bufalini Hospital, Cesena, Italy

(2) Department of Surgery, Radboud University Medical Center, Nijmegen, The Netherlands

(3) General Surgery, Hegde Hospital, Mangaluru, Karnataka, India

(4) Emergency Med. Dept., Radboud University Medical Center, Nijmegen, The Netherlands

(5) Second Department of Surgery, Meilahti Hospital, Helsinki, Finland (6) General and Emergency Surgery, Milano-Bicocca University, School of Medicine and Surgery, Monza, Italy

(7) Hospital Universitário Terezinha De Jesus, Faculdade De Ciências Médicas E Da Saúde De Juiz De Fora (Suprema) Brazil

(8) General, Emergency and Trauma Surgery Dept., Papa Giovanni XXIII Hospital, Bergamo, Italy

(9) Chirurgie Digestive, CHUGA-CHU Grenoble Alpes, Grenoble, France

(10) General Surgery dept., Pavia University Hospital, Pavia, Italy

(11) Division of General Surgery Rambam Health Care Campus Haifa, Israel
(12) Department of Clinical and Experimental Sciences, Surgical Clinic, University of Brescia, Brescia, Italy.

(13) Emergency and Trauma Surgery, Maggiore Hospital, Parma, Italy

(14) Emergency and Trauma Surgery dept., Niguarda Hospital, Milano, Italy

(15) General Surgery Dept., Aviano Hospital, Aviano, Italy

(16) General Surgery Dept., Forlì Hospital, Forli, Italy

(17) Department of General and Thoracic Surgery, University Hospital of Giessen, Giessen, Germany.

(18) Emergency Med. Dept., Verona Hospital, Verona, Italy

(19) London Health Sciences Centre, London, ON Canada.

(20) Unit of Digestive Surgery, HPB Surgery and Liver Transplant, Henri

Mondor Hospital, Créteil, France

(21) Trauma/ Acute Care Surgery \& Surgical Critical Care, University of Campinas, Campinas, Brazil

(22) General and Emergency Surgery dept., Montevideo hospital,

Montevideo, Paraguay

(23) Trauma and Surgical Critical Care, University of Michigan Health System,

East Medical Center Drive, Ann Arbor, MI, USA

(24) 3rd Department of Surgery, Attiko Hospital, National \& Kapodistrian University of Athens, Greece

(25) General Surgery Dept., Hadassah Medical Centre, Jerusalem, Israel

(26) Trauma and Acute Care Surgery and Surgical Critical Care Trauma,

Department of Surgery University of California, Davis, USA

(27) Trauma Sugery, Hamad General Hospital, Doha, Qatar

(28) General and Tauma Surgery, Virginia Commonwealth University, Richmond, Virginia, USA

(29) Dept. of Cardiothoracic and Vascular Surgery \& Dept. Of Surgery Örebro University Hospital and Örebro University, Sweden

(30) Department of General Surgery, Riverside University Health System Medical Center, Moreno Valley, (California) USA

\section{Authors' contributions}

$F C$, EM, YC, WB, AL, YM, FK, AP, GPF, MS, LA, GA, AK, FAZ, IW, DW, EP, ML, CA, VM, VR, RC, VK, ACM, MB, CO, MC, FM, BS, JM, RM, IDC, FC, and WSES Expert Panel: manuscript conception and draft critically revised the manuscript and contribute to important scientific knowledge giving the final approval.

\section{Funding}

None.

Availability of data and materials

Not applicable.

Ethics approval and consent to participate

Not applicable.

Consent for publication

Not applicable.

\section{Competing interests}

The authors declare that they have no competing interests. (*: NOM should only be attempted in centers capable of a precise diagnosis of the severity of kidney injuries and capable of intensive management (close clinical observation and hemodynamic monitoring in a high dependency/intensive care environment, including serial clinical examination and laboratory assay, with immediate access to diagnostics, interventional radiology and surgery and immediately available access to blood and blood products or alternatively in presence of a rapid centralization system in those patients amenable to be transferred; @: Hemodynamic instability in adults is considered the condition in which patient has an admission systolic blood pressure $<90 \mathrm{mmHg}$ with evidence of skin vasoconstriction (cool, clammy, decreased capillary refill), altered level of consciousness and/or shortness of breath, or $>90 \mathrm{mmHg}$ but requiring bolus infusions/transfusions and/or vasopressor drugs and/or admission base excess (BE) $>-5 \mathrm{mmol} / \mathrm{l}$ and/or shock index > 1 and/or transfusion requirement of at least 4-6 Units of packed red blood cells within the first $24 \mathrm{~h}$; moreover transient responder patients (those showing an initial response to adequate fluid resuscitation, and then signs of ongoing loss and perfusion deficits) and more in general those responding to therapy but not amenable of sufficient stabilization to be undergone to interventional radiology treatments. In pediatric patients: Hemodynamic stability is considered systolic blood pressure of $90 \mathrm{mmHg}$ 
plus twice the child's age in years (the lower limit is inferior to $70 \mathrm{mmHg}$ plus twice the child's age in years, or inferior to $50 \mathrm{mmHg}$ in some studies), Stabilized or acceptable hemodynamic status is considered in children with a positive response to fluids resuscitation: 3 boluses of $20 \mathrm{~mL} / \mathrm{kg}$ of crystalloid replacement should be administered before blood replacement; positive response can be indicated by the heart rate reduction, the sensorium clearing, the return of peripheral pulses and normal skin color, an increase in blood pressure and urinary output, and an increase in warmth of extremity. Clinical judgment is fundamental in evaluating children.

\section{Author details}

${ }^{1}$ General, Emergency and Trauma Surgery, Pisa University Hospital, Via Paradisia, 56124 Pisa, Italy. ${ }^{2}$ Trauma Surgery, Denver Health, Denver, CO, USA. ${ }^{3}$ Division of General Surgery Rambam Health Care Campus, Haifa, Israel. ${ }^{4}$ Trauma Surgery Dept., Scripps Memorial Hospital, La Jolla, California, USA. ${ }^{5}$ General Surgery Dept., Mehilati Hospital, Helsinki, Finland. ${ }^{6}$ Department of Emergency and Critical Care Medicine, Chiba University Hospital, Chiba, Japan. ${ }^{7}$ Urology Department, University of Colorado, Denver, USA. ${ }^{8}$ Surgery Department, University of Pittsburgh, Pittsburgh, PA, USA. 'Trauma/Acute Care Surgery \& Surgical Critical Care, University of Campinas, Campinas, Brazil. ${ }^{10}$ General and Emergency Surgery, Macerata Hospital, Macerata, Italy. ${ }^{11}$ General, Emergency and Trauma Surgery Department, Bufalini Hospital, Cesena, Italy. ${ }^{12}$ Department of Surgery, Zagreb University Hospital Centre and School of Medicine, University of Zagreb, Zagreb, Croatia. ${ }^{13}$ General, Acute Care, Abdominal Wall Reconstruction, and Trauma Surgery, Foothills Medical Centre, Calgary, Alberta, Canada. ${ }^{14}$ Department of Surgery, College of Medicine and Health Sciences, UAE University, Al-Ain, United Arab Emirates. ${ }^{15}$ Department of Surgery, DHS Hospitals, Srinagar, Kashmir, India. ${ }^{16}$ Department of General Surgery, Royal Perth Hospital, Perth, Australia. ${ }^{17} 3 \mathrm{rd}$ Department of Surgery, Attiko Hospital, National \& Kapodistrian University of Athens, Athens, Greece. ${ }^{18}$ General Surgery, "General Calixto García", Habana Medicine University, Havana, Cuba. ${ }^{19} \mathrm{Clin}$. Univ. de Chirurgie Digestive et de I'Urgence, CHUGA-CHU Grenoble Alpes UGA-Université Grenoble Alpes, Grenoble, France. ${ }^{20}$ General and Trauma Surgery Department, Pietermaritzburg Hospital, Pietermaritzburg, South Africa. ${ }^{21}$ General and Emergency Surgery, Sergei Kirov Military Academy, Saint Petersburg, Russia. ${ }^{22}$ Department of General Surgery, Riverside University Health System Medical Center, Moreno Valley, CA, USA. ${ }^{23}$ General Surgery Department, Mozir City Hospital, Mozir, Belarus. ${ }^{24}$ Department of Surgery and Obstetrics and Gynecology, University of Buea, Buea, Cameroon. ${ }^{25}$ Trauma and Acute Care Surgery, Fundacion Valle del Lili, Cali, Colombia. ${ }^{26}$ General and Emergency Surgery Department, Montevideo Hospital, Montevideo, Paraguay. ${ }^{27}$ General Surgery Department, Medical University, University Hospital St George, Plovdiv, Bulgaria. ${ }^{28}$ Department of Emergency and Critical Care Medicine, Saint-Marianna University School of Medicine, Kawasaki, Japan. ${ }^{29}$ Department of Surgery, Harborview Medical Centre, Seattle, USA. ${ }^{30}$ Department of Surgical Sciences and Advanced Technologies "GF Ingrassia", Cannizzaro Hospital, University of Catania, Catania, Italy. ${ }^{31}$ Emergency and Trauma Surgery, Maggiore Hospital, Parma, Italy.

Received: 10 September 2019 Accepted: 23 October 2019 Published online: 02 December 2019

\section{References}

1. Veeratterapillay R, Fuge $O$, Haslam P, Harding C, Thorpe A. Renal trauma. J Clin Urol. 2017;10:379-90.

2. Grimsby GM, Voelzke B, Hotaling J, Sorensen MD, Koyle M, Jacobs MA Demographics of pediatric renal trauma. J Urol. 2014;192:1498-502.

3. Viola TA. Closed Kidney Injury. Clin Sports Med. 2013;32:219-27.

4. Brown SL, Elder JS, Spirnak JP. Are pediatric patients more susceptible to major renal injury from blunt trauma? A comparative study. J Urol. 1998;160:138-40.

5. Cabrera Castillo PM, Martínez-Piñeiro L, Maestro MÁ, De la Peña JJ. Evaluation and treatment of kidney penetrating wounds. Ann Urol (Paris). 2006;40:297-308.

6. Coccolini F, Catena F, Kluger Y, Sartelli M, Baiocchi G, Ansaloni L, et al. Abdominopelvic trauma: from anatomical to anatomo-physiological classification. World J Emerg Surg. 2018;13:50.

7. Coccolini F, Montori G, Catena F, Kluger Y, Biffl W, Moore EE, et al. Splenic trauma: WSES classification and guidelines for adult and pediatric patients. World J Emerg Surg. 2017;12:40.

8. Coccolini F, Catena F, Moore EE, Ivatury R, Biffl W, Peitzman A, et al. WSES classification and guidelines for liver trauma. World J Emerg Surg. 2016;11:50.
9. Coccolini F, Stahel PF, Montori G, Biffl W, Horer TM, Catena F, et al. Pelvic trauma: WSES classification and guidelines. World J Emerg Surg. 2017;12:5.

10. Yeung LL, Brandes SB. Contemporary management of renal trauma: differences between urologists and trauma surgeons. J Trauma Acute Care Surg. 2012;72:68-75 discussion 75-7.

11. Oxford Centre for Evidence-based Medicine - Levels of Evidence (March 2009) - CEBM [Internet]. Available from: http://www.cebm.net/oxford-centreevidence-based-medicine-levels-evidence-march-2009/.

12. Cameron JL. Current surgical therapy. Philadelphia: Elsevier Mosby; 2004.

13. Brandes SB, McAninch JW. Renal Trauma: A Practical Guide to Evaluation and Management. Sci World J. 2004;4:31-40.

14. Smith JK, Kenney PJ. Imaging of renal trauma. Radiol Clin N Am. 2003;41:1019-35.

15. Sica G, Bocchini G, Guida F, Tanga M, Guaglione M, Scaglione M. Multidetector computed tomography in the diagnosis and management of renal trauma. Radiol Med. 2010;115:936-49.

16. Kautza $B$, Zuckerbraun $B$, Peitzman AB. Management of blunt renal injury: what is new? Eur J Trauma Emerg Surg. 2015:41:251-8.

17. Alonso RC, Nacenta SB, Martinez PD, Guerrero AS, Fuentes CG. Kidney in danger: $C T$ findings of blunt and penetrating renal trauma. Radiographics. 2009;29:2033-53.

18. Heyns CF. Renal trauma: indications for imaging and surgical exploration. BJU Int. 2004;93:1165-70.

19. Stein JP, Kaji DM, Eastham J, Freeman JA, Esrig D, Hardy BE. Blunt renal trauma in the pediatric population: indications for radiographic evaluation. Urology. 1994;44:406-10.

20. Rathaus V, Pomeranz A, Shapiro-Feinberg M, Zissin R. Isolated severe renal injuries after minimal blunt trauma to the upper abdomen and flank: CT findings. Emerg Radiol. 2004;10:190-2.

21. Bixby SD, Callahan MJ, Taylor GA. Imaging in Pediatric Blunt Abdominal Trauma. Semin Roentgenol. 2008;43:72-82.

22. Fernández-Ibieta M. Renal Trauma in Pediatrics: A Current Review. Urology. 2018;113:171-8

23. Lambert SM. Pediatric urological emergencies. Pediatr Clin N Am. 2012;59:965-76.

24. Raz O, Haifler M, Copel L, Lang E, Abu-Kishk I, Eshel G, et al. Use of adult criteria for slice imaging may limit unnecessary radiation exposure in children presenting with hematuria and blunt abdominal trauma. Urology. 2011;77:187-90.

25. Fraser JD, Aguayo P, Ostlie DJ, St. Peter SD. Review of the evidence on the management of blunt renal trauma in pediatric patients. Pediatr Surg Int. 2009;25:125-32

26. Nguyen MM, Das S. Pediatric renal trauma. Urology. 2002;59:762-6 discussion 766-767.

27. Ceylan H, Gunsar C, Etensel B, Sencan A, Karaca I, Mir E. Blunt renal injuries in Turkish children: a review of 205 cases. Pediatr Surg Int. 2003;19:710-4.

28. Onen A, Kaya M, Cigdem MK, Otçu S, Oztürk H, Dokucu Al. Blunt renal trauma in children with previously undiagnosed pre-existing renal lesions and guidelines for effective initial management of kidney injury. BJU Int. 2002;89:936-41.

29. Stalker HP, Kaufman RA, Stedje K. The significance of hematuria in children after blunt abdominal trauma. Am J Roentgenol. 1990;154:569-71.

30. Brown SL, Haas C, Dinchman KH, Elder JS, Spirnak JP. Radiologic evaluation of pediatric blunt renal trauma in patients with microscopic hematuria. World J Surg. 2001:25:1557-60.

31. Goodacre B, van Sonnenberg E. Radiologic Evaluation of Renal Trauma: Part 1. J Intensive Care Med. 2000;15:90-8 SAGE PublicationsSage CA: Los Angeles.

32. Andronikou S, Bertelsmann J. CT scanning--essential for conservative management of paediatric blunt abdominal trauma. S Afr Med J. 2002;92:35-8.

33. Morey AF, Bruce JE, MCAninch JW. Efficacy of radiographic imaging in pediatric blunt renal trauma. J Urol. 1996;156:2014-8.

34. Perez-Brayfield MR, Gatti JM, Smith EA, Broecker B, Massad C, Scherz H, et al. Blunt traumatic hematuria in children. Is a simplified algorithm justified? J Urol. 2002;167:2543-6 discussion 2546-7.

35. Santucci RA, McAninch JM. Grade IV renal injuries: evaluation, treatment, and outcome. World J Surg. 2001;25:1565-72.

36. Brandes SB, McAninch JW. Urban free falls and patterns of renal injury: a 20-year experience with 396 cases. J Trauma. 1999;47:643-9 discussion 649-50.

37. Guareschi BLV, Stahlschmidt CMM, Becker K, Batista MFS, Buso PL, Von Bahten LC. Epidemiological analysis of polytrauma patients with kidney injuries in a university hospital. Rev Col Bras Cir. 2015;42:385.

38. Gerstenbluth RE, Spirnak JP, Elder JS. Sports participation and high grade renal injuries in children. J Urol. 2002;168:2575-8. 
39. Patel DP, Redshaw JD, Breyer BN, Smith TG, Erickson BA, Majercik SD, et al. High-grade renal injuries are often isolated in sports-related trauma. Injury. 2015;46:1245-9.

40. Kurtz MP, Eswara JR, Vetter JM, Nelson CP, Brandes SB. Blunt Abdominal Trauma from Motor Vehicle Collisions from 2007 to 2011 Renal Injury Probability and Severity in Children versus Adults. J Urol. 2017;197:906-10.

41. Gross JA, Lehnert BE, Linnau KF, Voelzke BB, Sandstrom CK. Imaging of Urinary System Trauma. Radiol Clin N Am. 2015;53:773-88.

42. Pereira BMT, Ogilvie MP, Gomez-Rodriguez JC, Ryan ML, Pena D, Marttos AC, et al. A review of ureteral injuries after external trauma. Scand J Trauma Resusc Emerg Med. 2010;18:6.

43. Serafetinides E, Kitrey ND, Djakovic N, Kuehhas FE, Lumen N, Sharma DM, et al. Review of the current management of upper urinary tract injuries by the EAU Trauma Guidelines Panel. Eur Urol. 2015;67:930-6.

44. Brandes S, Coburn M, Armenakas N, McAninch J. Diagnosis and management of ureteric injury: an evidence-based analysis. BJU Int. 2004:94:277-89.

45. Zinman LN, Vanni AJ. Surgical Management of Urologic Trauma and latrogenic Injuries. Surg Clin North Am. 2016;96:425-39.

46. Serkin FB, Soderdahl DW, Hernandez J, Patterson M, Blackbourne L, Wade CE. Combat Urologic Trauma in US Military Overseas Contingency Operations. J Trauma Inj Infect Crit Care. 2010;69:S175-8.

47. Siram SM, Gerald SZ, Greene WR, Hughes K, Oyetunji TA, Chrouser K, et al. Ureteral trauma: patterns and mechanisms of injury of an uncommon condition. Am J Surg. 2010;199:566-70.

48. Ramchandani P, Buckler PM. Imaging of Genitourinary Trauma. Am J Roentgenol. 2009;192:1514-23.

49. Mirvis SE. Diagnostic imaging of the urinary system following blunt trauma. Clin Imaging. 1989;13:269-80.

50. Zaid UB, Bayne DB, Harris CR, Alwaal A, McAninch JW, Breyer BN. Penetrating Trauma to the Ureter, Bladder, and Urethra. Curr Trauma Reports. 2015;1:119-24

51. Santucci RA, Bartley JM. Urologic trauma guidelines: a 21st century update. Nat Rev Urol. 2010;7:510-9.

52. Matlock KA, Tyroch AH, Kronfol ZN, McLean SF, Pirela-Cruz MA. Blunt traumatic bladder rupture: a 10-year perspective. Am Surg. 2013;79:589-93.

53. Urry RJ, Clarke DL, Bruce JL, Laing GL. The incidence, spectrum and outcomes of traumatic bladder injuries within the Pietermaritzburg Metropolitan Trauma Service. Injury. 2016;47:1057-63.

54. Gomez RG, Ceballos L, Coburn M, Corriere JN, Dixon CM, Lobel B, et al. Consensus statement on bladder injuries. BJU Int. 2004;94:27-32.

55. Sivit CJ, Cutting JP, Eichelberger MR. CT diagnosis and localization of rupture of the bladder in children with blunt abdominal trauma: significance of contrast material extravasation in the pelvis. AJR Am J Roentgenol. 1995;164:1243-6.

56. Brandes S, Borrelli J. Pelvic fracture and associated urologic injuries. World J Surg. 2001;25:1578-87.

57. Kong JPL, Bultitude MF, Royce P, Gruen RL, Cato A, Corcoran NM. Lower urinary tract injuries following blunt trauma: a review of contemporary management. Rev Urol. 2011;13:119-30.

58. Rosenstein DI, Alsikafi NF. Diagnosis and classification of urethral injuries. Urol Clin North Am. 2006;33:73-85 vi-vii.

59. Bjurlin MA, Kim DY, Zhao LC, Palmer CJ, Cohn MR, Vidal PP, et al. Clinical characteristics and surgical outcomes of penetrating external genital injuries. J Trauma Acute Care Surg. 2013;74:839-44.

60. Lumen N, Hoebeke P, Willemsen P, De Troyer B, Pieters R, Oosterlinck W. Etiology of Urethral Stricture Disease in the 21st Century. J Urol. 2009;182:983-7.

61. Palminteri E, Berdondini E, Verze P, De Nunzio C, Vitarelli A, Carmignani L. Contemporary Urethral Stricture Characteristics in the Developed World. Urology. 2013;81:191-7.

62. Basta AM, Blackmore CC, Wessells $\mathrm{H}$. Predicting urethral injury from pelvic fracture patterns in male patients with blunt trauma. J Urol. 2007;177:571-5.

63. McGeady JB, Breyer BN. Current epidemiology of genitourinary trauma. Urol Clin North Am. 2013;40:323-34

64. Tausch TJ, Cavalcanti AG, Soderdahl DW, Favorito L, Rabelo P, Morey AF. Gunshot wound injuries of the prostate and posterior urethra: reconstructive armamentarium. J Urol. 2007;178:1346-8.

65. Goldman SM, Sandler CM, Corriere JN, McGuire EJ. Blunt urethral trauma: a unified, anatomical mechanical classification. J Urol. 1997;157:85-9.

66. Obenauer S, Plothe K-D, Ringert RH, Heuser M. Imaging of genitourinary trauma. Scand J Urol Nephrol. 2006;40:416-22.
67. Brandes S. Initial Management of Anterior and Posterior Urethral Injuries. Urol Clin North Am. 2006;33:87-95.

68. Kommu SS, Illahi I, Mumtaz F. Patterns of urethral injury and immediate management. Curr Opin Urol. 2007;17:383-9.

69. Becker A, Lin G, McKenney MG, Marttos A, Schulman CI. Is the FAST exam reliable in severely injured patients? Injury. 2010;41:479-83.

70. Kirkpatrick AW, Sirois M, Laupland KB, Liu D, Rowan K, Ball CG, et al. Handheld thoracic sonography for detecting post-traumatic pneumothoraces: the Extended Focused Assessment with Sonography for Trauma (EFAST). J Trauma. 2004;57:288-95.

71. Kirkpatrick AW, Sirois M, Ball CG, Laupland KB, Goldstein L, Hameed M, et al. The hand-held ultrasound examination for penetrating abdominal trauma. Am J Surg. 2004;187:660-5.

72. Thorelius L. Emergency real-time contrast-enhanced ultrasonography for detection of solid organ injuries. Eur Radiol. 2007;17(Suppl 6):F107-11.

73. Sato M, Yoshii H. Reevaluation of ultrasonography for solid-organ injury in blunt abdominal trauma. J Ultrasound Med. 2004;23:1583-96.

74. Jalli R, Kamalzadeh N, Lotfi M, Farahangiz S, Salehipour M. Accuracy of sonography in detection of renal injuries caused by blunt abdominal trauma: a prospective study. Ulus Travma Acil Cerrahi Derg. 2009;15:23-7.

75. Heller MT, Schnor N. MDCT of renal trauma: correlation to AAST organ injury scale. Clin Imaging. 2014;38:410-7.

76. McGahan JP, Richards JR, Jones CD, Gerscovich EO. Use of ultrasonography in the patient with acute renal trauma. J Ultrasound Med. 1999;18:207-13 quiz 215-6.

77. Eeg KR, Khoury AE, Halachmi S, Braga LHP, Farhat WA, Bägli DJ, et al. Single center experience with application of the ALARA concept to serial imaging studies after blunt renal trauma in children--is ultrasound enough? J Urol. 2009;181:1834-40 discussion 1840.

78. Poletti PA, Kinkel K, Vermeulen B, Irmay F, Unger P-F, Terrier F. Blunt Abdominal Trauma: Should US Be Used to Detect Both Free Fluid and Organ Injuries? Radiology. 2003;227:95-103.

79. Nicolau C, Ripollés T. Contrast-enhanced ultrasound in abdominal imaging. Abdom Imaging. 2012;37:1-19.

80. Wang D, Lv F, Luo Y, An L, Li J, Xie X, et al. Comparison of transcutaneous contrast-enhanced ultrasound-guided injected hemostatic agents with traditional surgery treatment for liver, spleen and kidney trauma: a retrospective study. Hepatogastroenterology. 2012;59:2021-6.

81. Catalano O, Aiani L, Barozzi L, Bokor D, De Marchi A, Faletti C, et al. CEUS in abdominal trauma: multi-center study. Abdom Imaging. 2009;34:225-34.

82. Armstrong LB, Mooney DP, Paltiel H, Barnewolt C, Dionigi B, Arbuthnot M, et al. Contrast enhanced ultrasound for the evaluation of blunt pediatric abdominal trauma. J Pediatr Surg. 2018;53:548-52.

83. Sessa B, Trinci M, lanniello S, Menichini G, Galluzzo M, Miele V. Blunt abdominal trauma: role of contrast-enhanced ultrasound (CEUS) in the detection and staging of abdominal traumatic lesions compared to US and CE-MDCT. Radiol Med. 2015;120:180-9.

84. Menichini G, Sessa B, Trinci M, Galluzzo M, Miele V. Accuracy of contrastenhanced ultrasound (CEUS) in the identification and characterization of traumatic solid organ lesions in children: a retrospective comparison with baseline US and CE-MDCT. Radiol Med. 2015;120:989-1001.

85. Miele V, Piccolo CL, Galluzzo M, lanniello S, Sessa B, Trinci M. Contrast-enhanced ultrasound (CEUS) in blunt abdominal trauma. Br J Radiol. 2016;89:20150823.

86. Valentino M, Ansaloni L, Catena F, Pavlica P, Pinna AD, Barozzi L. Contrastenhanced ultrasonography in blunt abdominal trauma: considerations after 5 years of experience. Radiol Med. 2009;114:1080-93.

87. Valentino M, De Luca C, Galloni SS, Branchini M, Modolon C, Pavlica P, et al. Contrast-enhanced US evaluation in patients with blunt abdominal trauma. J Ultrasound. 2010;13:22-7.

88. Regine G, Atzori M, Miele V, Buffa V, Galluzzo M, Luzietti M, et al. Secondgeneration sonographic contrast agents in the evaluation of renal trauma. Radiol Med. 2007;112:581-7.

89. Valentino M, Serra C, Pavlica P, Barozzi L. Contrast-enhanced ultrasound for blunt abdominal trauma. Semin Ultrasound CT MR. 2007;28:130-40.

90. Xu R-X, Li Y-K, Li T, Wang S-S, Yuan G-Z, Zhou Q-F, et al. Real-time 3dimensional contrast-enhanced ultrasound in detecting hemorrhage of blunt renal trauma. Am J Emerg Med. 2013;31:1427-31.

91. Porter JM, Singh $Y$. Value of computed tomography in the evaluation of retroperitoneal organ injury in blunt abdominal trauma. Am J Emerg Med. 1998; 16:225-7.

92. Buckley JC, MCAninch JW. The diagnosis, management, and outcomes of pediatric renal injuries. Urol Clin North Am. 2006;33:33-40. 
93. Kailidou E, Pikoulis E, Katsiva V, Karavokyros IG, Athanassopoulou A, Papakostantinou I, et al. Contrast-enhanced spiral $C T$ evaluation of blunt abdominal trauma. JBR-BTR. 2005;88:61-5.

94. Scialpi M, Scaglione M, Angelelli G, Lupattelli L, Resta MC, Resta M, et al. Emergencies in the retroperitoneum: assessment of spread of disease by helical CT. Eur J Radiol. 2004;50:74-83.

95. Osman NMM, Eissawy MG, Mohamed AM. The role of multi-detector computed tomography with 3D images in evaluation and grading of renal trauma. Egypt Radiol Nucl Med. 2016;47:305-17 No longer published by Elsevier.

96. Fanney DR, Casillas J, Murphy BJ. CT in the diagnosis of renal trauma. Radiographics. 1990;10:29-40.

97. Nuñez D, Becerra JL, Fuentes D, Pagson S. Traumatic occlusion of the renal artery: helical CT diagnosis. Am J Roentgenol. 1996;167:777-80.

98. Razali MR, Azian AA, Amran AR, Azlin S. Computed tomography of blunt renal trauma. Singap Med J. 2010;51:468-73 quiz 474.

99. Kawashima A, Sandler CM, Corl FM, West OC, Tamm EP, Fishman EK, et al. Imaging of Renal Trauma: A Comprehensive Review. RadioGraphics. 2001;21:557-74.

100. McAndrew JD, Corriere JN. Radiographic evaluation of renal trauma: evaluation of 1103 consecutive patients. Br J Urol. 1994;73:352-4.

101. Michel LA, Lacrosse $M$, Decannière $L$, Rosière $A$, Vandenbossche $P$, Trigaux JP. Spiral computed tomography with three-dimensional reconstructions for severe blunt abdominal traumas: a useful complementary tool? Eur J Emerg Med. 1997:4:87-93.

102. Peng N, Wang X, Zhang Z, Fu S, Fan J, Zhang Y. Diagnosis value of multi-slice spiral CT in renal trauma. Zhang Y, editor. J Xray Sci Technol. 2016;24:649-55.

103. Bartley JM, Santucci RA. Computed tomography findings in patients with pediatric blunt renal trauma in whom expectant (nonoperative) management failed. Urology. 2012;80:1338-43.

104. Shirazi M, Sefidbakht S, Jahanabadi Z, Asadolahpour A, Afrasiabi MA. Is early reimaging $C T$ scan necessary in patients with grades III and IV renal trauma under conservative treatment? J Trauma. 2010;68:9-12.

105. McCombie SP, Thyer I, Corcoran NM, Rowling C, Dyer J, Le Roux A, et al. The conservative management of renal trauma: a literature review and practical clinical guideline from Australia and New Zealand. BJU Int. 2014;114:13-21.

106. Visrutaratna $P, N a-C h i a n g m a i$ W. Computed tomography of blunt abdominal trauma in children. Singap Med J. 2008:49:352-8 quiz 359.

107. Buckley JC, MCAninch JW. Pediatric renal injuries: management guidelines from a 25-year experience. J Urol. 2004;172:687-90 discussion 690.

108. Alsikafi NF, Rosenstein DI. Staging, evaluation, and nonoperative management of renal injuries. Urol Clin North Am. 2006;33:13-9 v.

109. Eastham JA, Wilson TG, Ahlering TE. Radiographic evaluation of adult patients with blunt renal trauma. J Urol. 1992;148:266-7.

110. Chong ST, Cherry-Bukowiec JR, Willatt JMG, Kielar AZ. Renal trauma: imaging evaluation and implications for clinical management. Abdom Radiol (New York). 2016;41:1565-79.

111. Leppäniemi A, Lamminen A, Tervahartiala P, Salo J, Haapiainen R, Lehtonen T. MRI and CT in blunt renal trauma: an update. Semin Ultrasound CT MR. 1997;18:129-35.

112. Leppäniemi AK, Kivisaari $A O$, Haapiainen RK, Lehtonen TA. Role of magnetic resonance imaging in blunt renal parenchymal trauma. Br J Urol. 1991;68:355-60.

113. Ortega SJ, Netto FS, Hamilton P, Chu P, Tien HC. CT scanning for diagnosing blunt ureteral and ureteropelvic junction injuries. BMC Urol. 2008;8:3.

114. Elliott SP, McAninch JW. Ureteral Injuries: External and latrogenic. Urol Clin North Am. 2006;33:55-66.

115. Best CD, Petrone $P$, Buscarini $M$, Demiray $S$, Kuncir E, Kimbrell B, et al. Traumatic ureteral injuries: a single institution experience validating the American Association for the Surgery of Trauma-Organ Injury Scale grading scale. J Urol. 2005;173:1202-5.

116. Morey AF, Brandes S, Dugi DD, Armstrong JH, Breyer BN, Broghammer JA, et al. Urotrauma: AUA Guideline. J Urol. 2014;192:327-35.

117. Quagliano PV, Delair SM, Malhotra AK. Diagnosis of blunt bladder injury: A prospective comparative study of computed tomography cystography and conventional retrograde cystography. J Trauma. 2006;61:410-21 discussion 421-2.

118. Shenfeld OZ, Gnessin E. Management of urogenital trauma: state of the art. Curr Opin Urol. 2011:21:449-54

119. Horstman WG, McClennan BL, Heiken JP. Comparison of computed tomography and conventional cystography for detection of traumatic bladder rupture. Urol Radiol. 1991;12:188-93.

120. Mundy AR, Andrich DE. Urethral trauma. Part I: introduction, history, anatomy, pathology, assessment and emergency management. BJU Int. 2011;108:310-27.
121. Figler BD, Figler B, Hoffler CE, Reisman W, Carney KJ, Moore T, et al. Multidisciplinary update on pelvic fracture associated bladder and urethral injuries. Injury. 2012;43:1242-9.

122. Koraitim MM. Pelvic fracture urethral injuries: the unresolved controversy. J Urol. 1999;161:1433-41.

123. Bryk DJ, Zhao LC. Guideline of guidelines: a review of urological trauma guidelines. BJU Int. 2016;117:226-34.

124. Chapple C, Barbagli G, Jordan G, Mundy AR, Rodrigues-Netto N, Pansadoro V, et al. Consensus statement on urethral trauma. BJU Int. 2004;93:1195-202.

125. Lumen N, Kuehhas FE, Djakovic N, Kitrey ND, Serafetinidis E, Sharma DM, et al. Review of the current management of lower urinary tract injuries by the EAU Trauma Guidelines Panel. Eur Urol. 2015;67:925-9.

126. Mundy AR, Andrich DE. Urethral trauma. Part II: Types of injury and their management. BJU Int. 2011;108:630-50.

127. Summerton DJ, Djakovic N, Kitrey ND, Kuehhas FE, Lumen N, Serafetinidis E, et al. Guidelines on Urological Trauma [Internet]. 2015. Available from: https://uroweb. org/wp-content/uploads/EAU-Guidelines-Urological-Trauma-2015-v2.pdf.

128. Sujenthiran A, Elshout PJ, Veskimae E, MacLennan S, Yuan Y, Serafetinidis E, et al. Is Nonoperative Management the Best First-line Option for High-grade Renal trauma? A Systematic Review. Eur Urol Focus. 2019;5(2):290-300.

129. Mingoli A, La Torre M, Migliori E, Cirillo B, Zambon M, Sapienza P, et al. Operative and nonoperative management for renal trauma: comparison of outcomes. A systematic review and meta-analysis. Ther Clin Risk Manag. 2017;13:1127-38.

130. Navsaria PH, Nicol AJ, Edu S, Gandhi R, Ball CG. Selective nonoperative management in 1106 patients with abdominal gunshot wounds: conclusions on safety, efficacy, and the role of selective CT imaging in a prospective single-center study. Ann Surg. 2015;261:760-4.

131. Prakash BSML, Puvvada S, Patil A, Nayak A, Nagaraj HK. Management of renal trauma a retrospective study--our experience. J Evol Med Dent Sci. 2015:4:14891-8 Akshantala Enterprises Private Limited.

132. Dagenais J, Leow JJ, Haider AH, Wang Y, Chung Bl, Chang SL, et al. Contemporary Trends in the Management of Renal Trauma in the United States: A National Community Hospital Population-based Analysis. Urology. 2016;97:98-104.

133. DuBose J, Inaba K, Teixeira PGR, Pepe A, Dunham MB, McKenney M. Selective non-operative management of solid organ injury following abdominal gunshot wounds. Injury. 2007;38:1084-90.

134. Oyo-Ita A, Chinnock P, Ikpeme IA. Surgical versus non-surgical management of abdominal injury. Cochrane Database Syst Rev. 2015;(11):CD007383.

135. Shoobridge JJ, Bultitude MF, Koukounaras J, Martin KE, Royce PL, Corcoran NM. A 9-year experience of renal injury at an Australian level 1 trauma centre. BJU Int. 2013;112(Suppl):53-60.

136. McClung CD, Hotaling JM, Wang J, Wessells H, Voelzke BB. Contemporary trends in the immediate surgical management of renal trauma using a national database. J Trauma Acute Care Surg. 2013;75:602-6.

137. Bjurlin MA, Jeng El, Goble SM, Doherty JC, Merlotti GJ. Comparison of Nonoperative Management With Renorrhaphy and Nephrectomy in Penetrating Renal Injuries. J Trauma Inj Infect Crit Care. 2011;71:1.

138. Gourgiotis S, Germanos S, Dimopoulos N, Vougas V, Anastasiou T, Baratsis S. Renal Injury: 5-Year Experience and Literature Review. Urol Int. 2006:77:97-103.

139. Goldman SM, Sandler CM. Urogenital trauma: imaging upper GU trauma. Eur J Radiol. 2004;50:84-95.

140. Al-Bareeq R, Zabar K, Al-Tantawi M. Conservative Management of Renal Trauma: Ten Years Experience. Bahrain Med Bull. 2006;28:34-38.

141. Cesar BP, Starling SV, Drumond DAF. Non operative management of renal gunshot wounds. Rev Col Bras Cir. 2013;40:330-4.

142. Skinner DV, Driscoll PA, Peter A. ABC of major trauma: Wiley-Blackwell; 2013.

143. Okur MH, Arslan S, Aydogdu B, Arslan MS, Goya C, Zeytun H, et al. Management of high-grade renal injury in children. Eur J Trauma Emerg Surg. 2017:43:99-104.

144. Pirinççi N, Kaba M, Geçit I, Günes M, Tanik S, Ceylan K. Conservative Approach in the Treatment of Renal Trauma in Children. Urol Int. 2014;92:215-8.

145. Davis KA, Reed RL, Santaniello J, Abodeely A, Esposito TJ, Poulakidas SJ, et al. Predictors of the Need for Nephrectomy After Renal Trauma. J Trauma Inj Infect Crit Care. 2006;60:164-70.

146. Santucci RA, Fisher MB. The literature increasingly supports expectant (conservative) management of renal trauma--a systematic review. J Trauma. 2005;59:493-503.

147. Stein DM, Santucci RA. An update on urotrauma. Curr Opin Urol. 2015;25(4): 323-30 
148. Moolman C, Navsaria PH, Lazarus J, Pontin A, Nicol AJ. Nonoperative management of penetrating kidney injuries: a prospective audit. J Urol. 2012;188:169-73.

149. Broghammer JA, Fisher MB, Santucci RA. Conservative Management of Renal Trauma: A Review. Urology. 2007;70:623-9.

150. Kitrey ND, Djakovic N, Kuehhas FE, Lumen N, Serafetinidis E, Shatma DM The 2018 Urological Trauma Guidelines [Internet]. 2018. Available from: https://uroweb.org/guideline/urological-trauma/

151. Al-Qudah HS, Santucci RA. Complications of renal trauma. Urol Clin North Am. 2006;33:41-53 vi.

152. Goldman SM, Sandler CM. Upper urinary tract trauma--current concepts. World J Urol. 1998;16:62-8.

153. Wessells H, McAninch JW, Meyer A, Bruce J. Criteria for nonoperative treatment of significant penetrating renal lacerations. J Urol. 1997;157:24-7.

154. Khan AR, Fatima N, Anwar K. Pattern and management of renal injuries at Pakistan Institute of Medical Sciences. J Coll Physician Surg Pakistan. 2010; 20:194197.

155. Pathak S, Cutinha P. Trauma to the genitourinary tract. Surg Elsevier. 2008; 26:165-71

156. Brandes SB, McAninch JW. Reconstructive surgery for trauma of the upper urinary tract. Urol Clin North Am. 1999;26:183-99 x.

157. Szmigielski W, Kumar R, Al Hilli S, Ismail M. Renal trauma imaging: Diagnosis and management. A pictorial review. Pol J Radiol. 2013;78:27-35.

158. Cutinha P, Venugopal S, Salim F. Genitourinary trauma. Surg Elsevier. 2013; 31:362-70.

159. Shewakramani S, Reed KC. Genitourinary trauma. Emerg Med Clin North Am. 2011;29:501-18.

160. Demetriades D, Hadjizacharia P, Constantinou C, Brown C, Inaba K, Rhee P et al. Selective Nonoperative Management of Penetrating Abdominal Solid Organ Injuries. Trans Meet Am Surg Assoc. 2006;124:285-93.

161. Buckley JC, MCAninch JW. Selective management of isolated and nonisolated grade IV renal injuries. J Urol. 2006;176:2498-502 discussion 2502.

162. Muller A, Rouvière O. Renal artery embolization-indications, technical approaches and outcomes. Nat Rev Nephrol. 2015;11:288-301.

163. Richter ER, Shriver CD. Delayed nephrectomy in grade $V$ renal injury with two interesting anatomic variations. Urology. 2001;58:607.

164. Wohlgemut JM, Jansen JO. The principles of non-operative management of penetrating abdominal injury. Trauma. 2013;15:289-300 SAGE PublicationsSage UK: London, England.

165. Metcalf M, Broghammer JA. Genitourinary trauma in geriatric patients. Curr Opin Urol. 2016;26:165-70.

166. Como JJ, Bokhari F, Chiu WC, Duane TM, Holevar MR, Tandoh MA, et al. Practice management guidelines for selective nonoperative management of penetrating abdominal trauma. J Trauma. 2010;68:721-33.

167. Taş H, Şenocak R, Kaymak Ş, Lapsekili E. Experiences of Conflict ZoneRelated Ballistic Renal Injury. Indian J Surg. 2016:78:299-303.

168. Zemp L, Mann U, Rourke KF. Perinephric Hematoma Size is Independently Associated with the Need for Urological Intervention in Multisystem Blunt Renal Trauma. J Urol. 2018;199:1283-8.

169. Keihani S, Anderson RE, Fiander M, McFarland MM, Stoddard GJ, Hotaling $\mathrm{JM}$, et al. Incidence of urinary extravasation and rate of ureteral stenting after high-grade renal trauma in adults: a meta-analysis. Transl Androl Urol. 2018;7:S169-78.

170. Lanchon C, Fiard G, Arnoux V, Descotes J-L, Rambeaud J-J, Terrier N, et al. High Grade Blunt Renal Trauma: Predictors of Surgery and Long-Term Outcomes of Conservative Management. A Prospective Single Center Study. J Urol. 2016;195:106-11.

171. Shariat SF, Roehrborn CG, Karakiewicz PI, Dhami G, Stage KH. Evidencebased validation of the predictive value of the American Association for the Surgery of Trauma kidney injury scale. J Trauma. 2007;62:933-9.

172. Chiron P, Hornez E, Boddaert G, Dusaud M, Bayoud Y, Molimard B, et al. Grade IV renal trauma management. A revision of the AAST renal injury grading scale is mandatory. Eur J Trauma Emerg Surg. 2016;42:237-41.

173. Malaeb B, Figler B, Wessells H, Voelzke BB. Should blunt segmental vascular renal injuries be considered an American Association for the Surgery of Trauma Grade 4 renal injury? J Trauma Acute Care Surg. 2014;76:484-7.

174. Wright JL, Nathens AB, Rivara FP, Wessells H. Renal and extrarenal predictors of nephrectomy from the national trauma data bank. J Urol. 2006;175:970-5 discussion 975.

175. Metro MJ, McAninch JW. Surgical exploration of the injured kidney: current indications and techniques. Int Braz J Urol. 2003;29:98-105.
176. Santucci RA. 2015 William Hunter Harridge lecture: how did we go from operating on nearly all injured kidneys to operating on almost none of them? Am J Surg. 2016;211:501-5.

177. Bittenbinder EN, Reed AB. Advances in renal intervention for trauma. Semin Vasc Surg. 2013;26:165-9

178. Prasad NH, Devraj R, Chandriah GR, Sagar SV, Reddy CR, Murthy PVLN. Predictors of nephrectomy in high grade blunt renal trauma patients treated primarily with conservative intent. Indian J Urol. 2014;30:158-60.

179. Keihani S, Xu Y, Presson AP, Hotaling JM, Nirula R, Piotrowski J, et al. Contemporary management of high-grade renal trauma: Results from the American Association for the Surgery of Trauma Genitourinary Trauma study. J Trauma Acute Care Surg. 2018;84:418-25.

180. Moses RA, Selph JP, Voelzke BB, Piotrowski J, Eswara JR, Erickson BA, et al. An American Association for the Surgery of Trauma (AAST) prospective multi-center research protocol: outcomes of urethral realignment versus suprapubic cystostomy after pelvic fracture urethral injury. Transl Androl Urol. 2018;7:512-20.

181. Hagiwara A, Sakaki S, Goto H, Takenega K, Fukushima H, Matuda H, et al. The role of interventional radiology in the management of blunt renal injury: a practical protocol. J Trauma. 2001;51:526-31.

182. Yuan K-C, Wong Y-C, Lin B-C, Kang S-C, Liu E-H, Hsu Y-P. Negative catheter angiography after vascular contrast extravasations on computed tomography in blunt torso trauma: an experience review of a clinical dilemma. Scand J Trauma Resusc Emerg Med. 2012;20:46.

183. Baghdanian AH, Baghdanian AA, Armetta A, Babayan RK, LeBedis CA, Soto JA, et al. Utility of MDCT findings in predicting patient management outcomes in renal trauma. Emerg Radiol. 2017;24:263-72.

184. Lin W-C, Lin C-H, Chen J-H, Chen Y-F, Chang C-H, Wu S-C, et al. Computed tomographic imaging in determining the need of embolization for highgrade blunt renal injury. J Trauma Acute Care Surg. 2013;74:230-5.

185. Huber J, Pahernik S, Hallscheidt P, Sommer CM, Wagener N, Hatiboglu G, et al. Selective transarterial embolization for posttraumatic renal hemorrhage: a second try is worthwhile. J Urol. 2011;185:1751-5.

186. Charbit J, Manzanera J, Millet I, Roustan J-P, Chardon P, Taourel P, et al. What Are the Specific Computed Tomography Scan Criteria That Can Predict or Exclude the Need for Renal Angioembolization After High-Grade Renal Trauma in a Conservative Management Strategy? J Trauma Inj Infect Crit Care. 2011;70:1219-128.

187. Nuss GR, Morey AF, Jenkins AC, Pruitt JH, Dugi DD, Morse B, et al. Radiographic predictors of need for angiographic embolization afte traumatic renal injury. J Trauma. 2009;67:578-82 discussion 582.

188. Breyer BN, McAninch JW, Elliott SP, Master VA. Minimally Invasive Endovascular Techniques to Treat Acute Renal Hemorrhage. J Urol. 2008; 179:2248-53.

189. Vozianov S, Sabadash M, Shulyak A. Experience of renal artery embolization in patients with blunt kidney trauma. Cent Eur J Urol. 2015;68:471-7.

190. Antunes-Lopes T, Pinto R, Morgado P, Madaleno P, Silva J, Silva C, et al. Intrarenal artery pseudoaneurysm after blunt abdominal trauma: a case report of successful superselective angioembolization. Res reports Urol. 2014;6:17-20.

191. Ichigi Y, Takaki N, Nakamura K, Sato S, Kato A, Matsuo Y, et al. Significance of hematoma size for evaluating the grade of blunt renal trauma. Int J Urol. 1999;6:502-8.

192. Fu C-Y, Wu S-C, Chen R-J, Chen Y-F, Wang Y-C, Chung P-K, et al. Evaluation of need for angioembolization in blunt renal injury: discontinuity of Gerota's fascia has an increased probability of requiring angioembolization. Am J Surg. 2010;199:154-9.

193. Hotaling JM, Sorensen MD, Smith TG, Rivara FP, Wessells H, Voelzke BB. Analysis of diagnostic angiography and angioembolization in the acute management of renal trauma using a national data set. J Urol. 2011;185:1316-20.

194. Aragona F, Pepe P, Patanè D, Malfa P, D'Arrigo L, Pennisi M. Management of severe blunt renal trauma in adult patients: a 10-year retrospective review from an emergency hospital. BJU Int. 2012;110:744-8.

195. van der Wilden GM, Velmahos GC, Joseph DK, Jacobs L, Debusk MG, Adams CA, et al. Successful nonoperative management of the most severe blunt renal injuries: a multicenter study of the research consortium of New England Centers for Trauma. JAMA Surg. 2013;148:924-31.

196. Thony F, Rodière M, Frandon J, Vendrell A, Jankowski A, Ghelfi J, et al. Polytraumatism and solid organ bleeding syndrome: The role of imaging. Diagn Interv Imaging. 2015;96:707-15.

197. Kitase M, Mizutani M, Tomita H, Kono T, Sugie C, Shibamoto Y. Blunt renal trauma: comparison of contrast-enhanced $C T$ and angiographic findings and the usefulness of transcatheter arterial embolization. Vasa. 2007;36:108-13. 
198. Mohsen T, El-Assmy A, El-Diasty T. Long-term functional and morphological effects of transcatheter arterial embolization of traumatic renal vascular injury. BJU Int. 2008;101:473-7.

199. Sugihara T, Yasunaga $H$, Horiguchi $H$, Nishimatsu $H$, Fukuhara $H$, Enomoto $Y$, et al. Management trends, angioembolization performance and multiorgan injury indicators of renal trauma from Japanese administrative claims database. Int J Urol. 2012;19:559-63.

200. Sarani B, Powell E, Taddeo J, Carr B, Patel A, Seamon M, et al. Contemporary comparison of surgical and interventional arteriography management of blunt renal injury. J Vasc Interv Radiol. 2011;22:723-8.

201. Morita S, Inokuchi S, Tsuji T, Fukushima T, Higami S, Yamagiwa T, et al. Arterial embolization in patients with grade-4 blunt renal trauma: evaluation of the glomerular filtration rates by dynamic scintigraphy with 99mTechnetium-diethylene triamine pentacetic acid. Scand J Trauma Resusc Emerg Med. 2010;18:11.

202. Saour M, Charbit J, Millet I, Monnin V, Taourel P, Klouche K, et al. Effect of renal angioembolization on post-traumatic acute kidney injury after highgrade renal trauma: a comparative study of 52 consecutive cases. Injury. 2014;45:894-901.

203. Eastham JA, Wilson TG, Larsen DW, Ahlering TE. Angiographic embolization of renal stab wounds. J Urol. 1992;148:268-70.

204. Stewart AF, Brewer ME, Daley BJ, Klein FA, Kim ED. Intermediate-Term Follow-Up of Patients Treated With Percutaneous Embolization for Grade 5 Blunt Renal Trauma. J Trauma Inj Infect Crit Care. 2010;69:468-70.

205. Brewer ME, Strnad BT, Daley BJ, Currier RP, Klein FA, Mobley JD, et al. Percutaneous embolization for the management of grade 5 renal trauma in hemodynamically unstable patients: initial experience. J Urol. 2009;181:1737-41.

206. Muir MT, Inaba K, Ong A, Barmparas G, Branco BC, Zubowicz EA, et al. The need for early angiography in patients with penetrating renal injuries. Eur J Trauma Emerg Surg. 2012;38:275-80.

207. Heyns CF, van Vollenhoven P. Increasing role of angiography and segmental artery embolization in the management of renal stab wounds. J Urol. 1992;147:1231-4.

208. Holden A. Abdomen—Interventions for solid organ injury. Injury. 2008;39: 1275-89.

209. Lopera JE, Suri R, Kroma G, Gadani S, Dolmatch B. Traumatic occlusion and dissection of the main renal artery: endovascular treatment. J Vasc Interv Radiol. 2011;22:1570-4.

210. Flugsrud $G B$, Brekke $M$, Røise O. Endovascular stent in the acute treatment of blunt renal arterial injury. J Trauma. 2005;59:243-5.

211. Tennankore KK, Kim SJ, Alwayn IPJ, Kiberd BA. Prolonged warm ischemia time is associated with graft failure and mortality after kidney transplantation. Kidney Int. 2016;89:648-58.

212. Heylen L, Pirenne J, Samuel U, Tieken I, Naesens M, Sprangers B, et al. The Impact of Anastomosis Time During Kidney Transplantation on Graft Loss: A Eurotransplant Cohort Study. Am J Transplant. 2017;17:724-32.

213. Kiankhooy A, Sartorelli KH, Vane DW, Bhave AD. Angiographic Embolization Is Safe and Effective Therapy for Blunt Abdominal Solid Organ Injury in Children. J Trauma. 2010;68:526-31.

214. Lin W-C, Lin C-H. The role of interventional radiology for pediatric blunt renal trauma. Ital J Pediatr. 2015;41:76.

215. Eassa W, El-Ghar MA, Jednak R, El-Sherbiny M. Nonoperative Management of Grade 5 Renal Injury in Children: Does It Have a Place? Eur Urol. 2010;57:154-63.

216. LeeVan E, Zmora O, Cazzulino F, Burke RV, Zagory J, Upperman JS. Management of pediatric blunt renal trauma. J Trauma Acute Care Surg. 2016;80:519-28.

217. Murphy GP, Gaither TW, Awad MA, Osterberg EC, Baradaran N, Copp HL, et al. Management of Pediatric Grade IV Renal Trauma. Curr Urol Rep. 2017;18:23.

218. Wenske S, Olsson CA, Benson MC. Outcomes of Distal Ureteral Reconstruction Through Reimplantation With Psoas Hitch, Boari Flap, or Ureteroneocystostomy for Benign or Malignant Ureteral Obstruction or Injury. Urology. 2013;82:231-6.

219. Koukouras D, Petsas T, Liatsikos E, Kallidonis P, Sdralis EK, Adonakis G, et al. Percutaneous Minimally Invasive Management of latrogenic Ureteral Injuries. J Endourol. 2010;24:1921-7.

220. Wirth GJ, Peter R, Poletti P-A, Iselin CE. Advances in the management of blunt traumatic bladder rupture: experience with 36 cases. BJU Int. 2010;106:1344-9.

221. Kim FJ, Chammas MF, Gewehr EV, Campagna A, Moore EE. Laparoscopic Management of Intraperitoneal Bladder Rupture Secondary to Blunt Abdominal Trauma Using Intracorporeal Single Layer Suturing Technique. J Trauma Inj Infect Crit Care. 2008;65:234-6.
222. Cinman NM, McAninch JW, Porten SP, Myers JB, Blaschko SD, Bagga HS, et al. Gunshot wounds to the lower urinary tract. J Trauma Acute Care Surg. 2013;74:725-31.

223. Volpe MA, Pachter EM, Scalea TM, Macchia RJ, Mydlo JH. Is there a difference in outcome when treating traumatic intraperitoneal bladder rupture with or without a suprapubic tube? J Urol. 1999;161:1103-5.

224. Parry NG, Rozycki GS, Feliciano DV, Tremblay LN, Cava RA, Voeltz Z, et al. Traumatic Rupture of the Urinary Bladder: Is the Suprapubic Tube Necessary? J Trauma Inj Infect Crit Care. 2003;54:431-6.

225. Tekgül S, Dogan H, Hoebeke P, Kovcara R, Nijman JM, Radmayr C, et al. EAU Guidelines on Paediatric Urology. 2016.

226. Elshout PJ, Veskimae E, MacLennan S, Yuan Y, Lumen N, Gonsalves M, et al. Outcomes of Early Endoscopic Realignment Versus Suprapubic Cystostomy and Delayed Urethroplasty for Pelvic Fracture-related Posterior Urethral Injuries: A Systematic Review. Eur Urol Focus. 2017;3:545-53.

227. Cline KJ, Mata JA, Venable DD, Eastham JA. Penetrating trauma to the male external genitalia. J Trauma. 1998;44:492-4.

228. Phonsombat S, Master VA, McAninch JW. Penetrating external genital trauma: a 30-year single institution experience. J Urol. 2008;180:192-5 discussion 195-6.

229. Leddy LS, Vanni AJ, Wessells H, Voelzke BB. Outcomes of Endoscopic Realignment of Pelvic Fracture Associated Urethral Injuries at a Level 1 Trauma Center. J Urol. 2012;188:174-8.

230. Elgammal MA. Straddle injuries to the bulbar urethra: management and outcome in 53 patients. Int Braz J Urol. 2009:35:450-8.

231. Mouraviev VB, Coburn M, Santucci RA. The treatment of posterior urethral disruption associated with pelvic fractures: comparative experience of early realignment versus delayed urethroplasty. J Urol. 2005;173:873-6.

232. Koraitim MM. Unsuccessful Outcomes After Posterior Urethroplasty: Definition, Diagnosis, and Treatment. Urology. 2012;79:1168-74.

233. Lumen N, Hoebeke P, De Troyer B, Ysebaert B, Oosterlinck W. Perineal Anastomotic Urethroplasty for Posttraumatic Urethral Stricture With or Without Previous Urethral Manipulations: A Review of 61 Cases With LongTerm Followup. J Urol. 2009:181:1196-200.

234. Flynn BJ, Delvecchio FC, Webster GD. Perineal repair of pelvic fracture urethral distraction defects: experience in 120 patients during the last 10 years. J Urol. 2003;170:1877-80.

235. Blankenship JC, Gavant ML, Cox CE, Chauhan RD, Gingrich JR. Importance of delayed imaging for blunt renal trauma. World I Surg. 2001;25:1561-4.

236. Breen KJ, Sweeney P, Nicholson PJ, Kiely EA, O'Brien MF. Adult Blunt Renal Trauma: Routine Follow-up Imaging Is Excessive. Urology. 2014;84:62-7.

237. Bukur M, Inaba K, Barmparas G, Paquet C, Best C, Lam L, et al. Routine Follow-Up Imaging of Kidney Injuries May Not Be Justified. J Trauma Inj Infect Crit Care. 2011;70:1229-33.

238. Dugi DD, Morey AF, Gupta A, Nuss GR, Sheu GL, Pruitt JH. American Association for the Surgery of Trauma grade 4 renal injury substratification into grades 4a (low risk) and 4b (high risk). J Urol. 2010;183:592-7.

239. Fischer W, Wanaselja A, Steenburg SD. JOURNAL CLUB: Incidence of Urinary Leak and Diagnostic Yield of Excretory Phase $C T$ in the Setting of Renal Trauma. AJR Am J Roentgenol. 2015;204:1168-72 quiz 1173.

240. Simmons JD, Haraway AN, Schmieg RE, Duchesne JD. Blunt renal trauma and the predictors of failure of non-operative management. J Miss State Med Assoc. 2010;51:131-3.

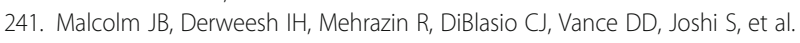
Nonoperative management of blunt renal trauma: is routine early follow-up imaging necessary? BMC Urol. 2008;8:11.

242. Davis P, Bultitude MF, Koukounaras J, Royce PL, Corcoran NM. Assessing the Usefulness of Delayed Imaging in Routine Followup for Renal Trauma. J Urol. 2010;184:973-7.

243. Santucci RA, Wessells H, Bartsch G, Descotes J, Heyns CF, McAninch JW, et al. Evaluation and management of renal injuries: consensus statement of the renal trauma subcommittee. BJU Int. 2004;93:937-54.

244. Margenthaler JA, Weber TR, Keller MS. Blunt renal trauma in children: experience with conservative management at a pediatric trauma center. J Trauma. 2002;52:928-32.

245. Bernard JJ. Renal Trauma: evaluation, management, and return to play. Curr Sports Med Rep. 2009;8:98-103.

246. Cianflocco AJ. Renal complications of exercise. Clin Sports Med. 1992;11:437-51.

247. Abdalati H, Bulas DI, Sivit CJ, Majd M, Rushton HG, Eichelberger MR. Blunt renal trauma in children: healing of renal injuries and recommendations for imaging follow-up. Pediatr Radiol. 1994;24:573-6. 
248. Keller MS, Eric Coln C, Garza JJ, Sartorelli KH, Christine Green M, Weber TR. Functional outcome of nonoperatively managed renal injuries in children. J Trauma. 2004;57:108-10 discussion 110.

249. Keller MS, Green MC. Comparison of short- and long-term functional outcome of nonoperatively managed renal injuries in children. J Pediatr Surg. 2009:44:144-7 discussion 147.

250. Mizzi A, Shabani A, Watt A. The role of follow-up imaging in paediatric blunt abdominal trauma. Clin Radiol. 2002;57:908-12.

251. Fuchs ME, Anderson RE, Myers JB, Wallis MC. The incidence of longterm hypertension in children after high-grade renal trauma. J Pediatr Surg. 2015;50:1919-21.

252. Henderson CG, Sedberry-Ross S, Pickard R, Bulas DI, Duffy BJ, Tsung D, et al. Management of high grade renal trauma: 20-year experience at a pediatric level I trauma center. J Urol. 2007;178:246-50 discussion 250.

253. Nance ML, Lutz N, Carr MC, Canning DA, Stafford PW. Blunt renal injuries in children can be managed nonoperatively: outcome in a consecutive series of patients. J Trauma. 2004;57:474-8 discussion 478.

254. Russell RS, Gomelsky A, McMahon DR, Andrews D, Nasrallah PF. Management of grade IV renal injury in children. J Urol. 2001;166:1049-50.

\section{Publisher's Note}

Springer Nature remains neutral with regard to jurisdictional claims in published maps and institutional affiliations.

Ready to submit your research? Choose BMC and benefit from:

- fast, convenient online submission

- thorough peer review by experienced researchers in your field

- rapid publication on acceptance

- support for research data, including large and complex data types

- gold Open Access which fosters wider collaboration and increased citations

- maximum visibility for your research: over $100 \mathrm{M}$ website views per year

At BMC, research is always in progress.

Learn more biomedcentral.com/submissions 